\title{
Cheer Up: \\ The Effect of Mood and Performance-Dependent Incentives on Creativity
}

\author{
Alisa G. Brink* \\ Professor \\ Virginia Commonwealth University \\ agbrink@vcu.edu \\ Bernhard E. Reichert \\ Assistant Professor \\ Virginia Commonwealth University \\ bereichert@,vcu.edu \\ J. Matthew Sarji \\ Doctoral Candidate \\ Virginia Commonwealth University \\ sarjijm@vcu.edu
}

October 2020

* Corresponding Author

This study received generous financial support from the School of Business and the accounting department at Virginia Commonwealth University. A prior version of this paper was the recipient of the Outstanding Manuscript Award at the 2020 Accounting, Behavior and Organizations Research Conference. The authors would like to thank the awards committee and the anonymous reviewers. The authors would also like to thank Lindsay Andiola, Jeremy Douthit, Oleg Korenok, Lisa LaViers, Don Moser, Steve Salterio, Jordan Samet, Todd Thornock, Yanjia Cynthia Yang, and workshop participants at the 2020 Accounting, Behavior and Organizations Research Conference, 2020 Management Accounting Section conference, Virginia Commonwealth University, participants in the Managerial Accounting Experimental Research Brown Bag, and the 2019 AAA/Deloitte J. Michael Cook Doctoral Consortium for their helpful comments and feedback. 


\title{
Cheer Up: \\ The Effect of Mood and Performance-Dependent Incentives on Creativity
}

\begin{abstract}
We use an experiment to investigate how incentive scheme and mood influence creative performance. The popular business press, as well as anecdotal evidence from artists and corporate practice, suggests that being in a positive mood leads to improved creativity, and companies that operate in knowledge industries invest considerable resources in measures aimed at improving employee mood. We extend the literature by examining the effect of mood on creativity in compensation contexts where participants create rebus puzzles with compensation that is either fixed, performance-dependent based on the quantity of output, or performancedependent based on the creativity of output. A relatively positive or negative mood is induced through the use of previously validated mood statements. We find a positive mood compared to a negative mood leads to more highly creative output (i.e., puzzles that receive top-quartile creativity ratings) for fixed compensation, but not for quantity-dependent or creativity-dependent compensation. These results are consistent with a crowding out of the effect of positive mood on creativity by performance-dependent compensation. Supplemental analysis indicates that this crowding out occurs after time passes rather than instantaneously, as mood significantly affects the creativity of the first puzzles produced regardless of compensation form.
\end{abstract}

Keywords: creativity; incentives; mood; subjective performance evaluations; experimental economics 


\section{Introduction}

The popular business press, as well as anecdotal evidence, suggests that positive mood improves creativity (e.g., Currey 2013; Bartleby 2019). Consistent with this notion, many companies in industries that rely on creativity for success invest substantial resources in strategies intended to improve employees' moods (McKee 2014; Pronto 2016; Preston 2017; Phelps 2019; Guggenmos 2020). Among firms that invest in mood-improving initiatives, there is a wide variation of compensation schemes offered to employees (e.g., fixed or performancedependent). While the impact of varying compensation schemes on creativity has received considerable attention in recent accounting research (Kachelmeier et al. 2008; Kachelmeier and Williamson 2010; Kachelmeier et al. 2019), the effect of mood in the context of different incentive schemes has thus far been unexplored (Byron and Khazanchi 2012). This study draws upon theory to develop and test predictions about the interactive effects of mood and certain features of performance-dependent compensation schemes on creative output. Specifically, in an experimental setting, we induce a relatively more positive or more negative mood and examine the effects of fixed compensation, compensation that rewards the quantity of output, and compensation that incentivizes highly creative output.

An array of research in psychology draws upon theory to examine the effects of positive and negative moods on creativity. ${ }^{1}$ This literature indicates that positive mood facilitates the retrieval of a larger, richer set of source material stored in memory as compared to non-positive mood (Mackie and Worth 1991; Isen 1993; Isen 2002). Further, positive mood induces a relaxed approach that prompts information processing strategies that facilitate creative quality by encouraging association and combination of seemingly remote concepts (e.g., Carnevale and Isen

\footnotetext{
${ }^{1}$ See Baas et al.(2008) and Davis (2009) for reviews of the creativity and mood literature.
} 
1986; Isen et al. 1987; Schwarz 1990; Estrada et al. 1994; Amabile et al. 2005; Friedman and Förster 2010). In comparison, negative mood is thought to induce an effortful and systematic processing strategy that is unlikely to translate into an output that is of high creative quality (Vosburg 1998). However, the strategies prompted by negative mood are capable of impacting the quantity of creative output. This suggests that negative mood leads to a larger quantity of low-quality creative output than positive mood.

We extend this research by examining the effects of performance-dependent compensation on the relation between mood and creativity with separate predictions for the effects of positive mood and negative mood. First, we predict that performance-dependent incentives may inhibit the relaxed and playful approach induced by positive mood, leading to a narrower conceptual focus and dampening the effect of positive mood on creative quality. Therefore, we predict that the most highly creative output will be observed when mood is positive and compensation is fixed as compared to other compensation schemes or negative mood.

Conversely, rather than a crowding out effect, performance-dependent compensation may have an additive effect or exacerbate the effects of negative mood on creative production. In particular, quantity-dependent incentives are consistent with the anticipated quantity-inducing effortful effects of negative mood. Due to this alignment, we expect a higher quantity of lowcreativity output for negative mood under quantity-dependent compensation as compared to fixed or creativity-dependent compensation.

We test our hypotheses with a $2 \times 3$ between-participants experiment. Our independent variables are mood (positive versus negative) and compensation scheme (fixed, creativity- 
dependent, and quantity-dependent). ${ }^{2}$ In the experimental session, participants first receive instructions for the experimental task, the creation of rebus puzzles, and their compensation scheme. After participants pass understanding checks, the mood induction procedure is initiated. Following prior literature (e.g., Cianci and Bierstaker 2009), our mood-induction procedure first involves participants reading either 60 positive or 60 negative Velten's Mood Statements (Velten 1968) as they are read aloud by a professional voice actress. ${ }^{3}$ The experimental task, which requires participants to produce rebus puzzles for 20 minutes, begins immediately after these statements conclude while classical music (validated for positive and negative mood induction) is played in the background.

Our results provide new insights regarding the effect of mood on creativity under performance-dependent versus fixed compensation. We find evidence that positive and negative mood differentially affect the creative quality and quantity of output in our task and that these effects depend upon the form of compensation.

Consistent with our first hypothesis, positive mood leads to more highly creative output (i.e., output with a creativity score in the top $25 \%$ of all rebus puzzles created) when compensation is fixed as compared to when compensation is based on either quantity or creativity. These results support the notion that performance-dependent compensation crowds out the effect of positive mood. In supplemental analyses, we examine the initial creativity output at the beginning of the production session measured as the first $25 \%$ of cards produced. We find that a positive mood leads to higher total initial creativity compared to a negative mood,

\footnotetext{
${ }^{2}$ For ease and clarity of exposition, we refer to our two mood states of interest as "positive" and "negative" throughout this paper. However, we note that these conditions might be more accurately described as relatively more positive or less positive moods. Mood occurs on a continuous scale, and the point at which mood shifts from positive to negative is indistinct. Further, the negative moods most applicable to our setting of interest (i.e., the workplace) are likely to be comparatively mild as compared to the negative moods that may occur in other settings or extreme situations (e.g., cases of serious illness, catastrophes, etc.).
} 
regardless of compensation scheme. Taken with our other results, these findings suggest that the positive-mood crowding-out effect does not occur instantaneously, but rather occurs over time.

Consistent with our second hypothesis, participants create a higher quantity of puzzles with low creativity scores (i.e., bottom $25 \%$ of creativity) when mood is negative and compensation is quantity-dependent as compared to other compensation conditions.

Supplemental analysis indicates that negative mood combined with creativity-dependent compensation leads to a higher quantity of medium-level creativity output (i.e., bottom $50 \%$ of creativity) as compared to other treatments. These results are consistent with theory that suggests that negative mood will lead to a prolonged effortful focus that results in a higher quantity of output of low creative quality.

Our findings contribute to the accounting literature in several ways. By examining the previously unstudied effects of mood and differing performance-dependent incentives on output for a creativity task, we offer several potential explanations for contradictory findings in the extant research on the effects of mood on creativity. First, our findings show that positive mood has a greater effect on the quality of creative output when compensation is fixed compared to when compensation is dependent on quantity or creativity. We refer to this as a positive-mood, crowding-out effect. Second, we show that the crowding out of positive mood does not happen instantaneously, but over time. Thus, studies that examine tasks with very short production time may not detect the crowding-out effect we observe. These factors - type of incentive and duration of task - hopefully contribute to reconciling contradictory findings in the literature on the effect of mood on creativity in psychology and management.

Our findings also help to reconcile divergent findings from creativity research in accounting and management. Research in accounting on creativity thus far has not found support 
for a negative effect of performance-dependent incentives on creativity, while a number of studies in the management and psychology literature show such an effect (Amabile 1982; Amabile et al. 1990). Our results indicate that when mood is positive, performance-dependent compensation leads to less output of high creative quality compared to fixed compensation. Theory suggests that this effect may be due to a reduced conceptual focus that occurs when compensation interferes with the relaxed playfulness induced by positive mood. Studies in psychology and management that find lower creativity due to imposed compensation may be documenting a similar effect.

Lastly, a number of studies in accounting suggest a superiority of quantity-dependent incentives over other forms of compensation. Specifically, quantity-dependent incentives lead to the same amount of highly creative or highest creativity output compared to other forms of compensation, while leading to additional mundane output (Kachelmeier et al. 2008;

Kachelmeier and Williamson 2010; Kachelmeier et al. 2019; Brink et al. 2020). Our findings indicate that, when mood is negative, quantity-dependent incentives lead to more low-quality creative output compared to other forms of compensation. Incentives that encourage such output may result in substantial costs to firms, such as costs of identifying and eliminating output of unacceptably low quality and reputational costs associated with mediocre or sub-par results. Depending on the marginal utility of low-creativity output, this presents a potential downside to the use of quantity-dependent incentives when mood is negative that has thus far not been considered in the literature on creative tasks. 


\section{Hypotheses Development}

\section{Mood and creativity}

We draw on psychology research to derive our predictions for the relative effects of mood on creativity. The literature defines positive mood as a subconscious state that is low in intensity and long in duration and characterized by feelings of high energy, pleasurable engagement, and overall well-being (CITE). Research suggests a positive relation between positive mood and creative performance due to two mechanisms. First, individuals are able to retrieve material from memory with greater ease when there is congruence between one's mood and the stored material in one's memory. This suggests that when one is in a positive mood, one can retrieve positive (i.e., congruent) material from memory with greater ease than non-positive (i.e., incongruent) material. As a survival tactic, humans are biologically hardwired to store more positive material in memory than non-positive material (e.g., Cramer 1968). Hence, on average, there is a larger and richer set of material stored in memory that is congruent with a positive mood than there is for a non-positive mood (Isen 1993). Further, creative ideas originate from ideas stored in one's memory that either already exist as complete ideas or are the result of a combination of several distinct ideas (Runco 2011). Taken together, this suggests that the quality of creative output will benefit from positive mood due to its ability to facilitate the retrieval of a larger, richer set of mental source material compared to non-positive mood.

Second, psychology research posits that a positive mood leads to a relaxed approach and a playful combination of ideas in obtaining novel solutions (Schwarz 1990; Clore et al. 1994; Fiedler 2000; Friedman and Förster 2010). Such an approach is beneficial to the production of creative output, as it prompts information processing strategies that facilitate creativity by encouraging the association and combination of seemingly remote concepts (e.g., Isen et al. 
1985; Isen et al. 1987; Ashby et al. 1999). In particular, broad conceptual attention, or the simultaneous activation of a wide range of memory content, is an information processing strategy prompted by positive mood that increases the possibility of one discovering useful and novel associations between concepts (Liu 2016). These associations, in turn, increase the likelihood of generating ideas that are original, innovative, and clever (e.g., Dru et al. 2008; Liu 2016).

Thus, a positive mood not only provides an individual access to a larger, richer, and more diverse set of ideas in memory, it also encourages information processing strategies that allow individuals to make the best use of the material retrieved. Thus, positive mood, in general, should facilitate the production of creative output that is of high creative quality (i.e., output that is considered highly creative). In contrast, a non-positive or negative mood makes retrieval of information from memory more difficult and induces a narrowed and focused perceptual view. Such constraints limit one's ability to generate ideas that are considered to be of high creative quality.

\section{The interactive effects of positive mood and compensation on highly creative output}

Although numerous studies have examined the effect of mood on creativity, the literature is silent on whether financial incentives moderate this relation. We draw from theory to examine this question. In particular, we examine fixed compensation and two forms of performancedependent incentives: quantity-dependent and creativity-dependent.

We propose that performance-dependent incentives disrupt the positive relation between positive mood and highly creative output. As discussed above, one of the primary reasons that psychology indicates that positive mood leads to high creativity is its facilitation of a relaxed playful approach and broad conceptual focus. However, performance-dependent incentives are 
designed to motivate individuals to heighten their focus on a particular desired aspect of their performance and direct their efforts in a strategic manner. As such, performance-dependent incentives may inhibit the relaxed playfulness that would otherwise occur from positive mood and lead to a narrower conceptual focus. This would suggest that the effectiveness of positive mood in inducing highly creative output will be less pronounced when combined with performance-dependent incentives, even when the goal of the incentive is to induce creative output. Individuals in non-positive or negative moods do not experience relaxed playfulness and broad conceptual focus. Therefore, the high creativity output for these individuals is expected to be low, and, therefore, there is less opportunity for performance dependent compensation to act as an interruptive force.

Therefore, we predict that individuals who are in a positive mood and operate under a fixed wage scheme (i.e., a wage scheme that is not performance-dependent) will be more highly creative than their negative mood counterparts. In contrast, individuals who are in a positive mood and operate under a performance-dependent compensation scheme will be no more highly creative than their negative mood counterparts. Taken together, this suggests that performancedependent incentives will effectively crowd out the positive effects of mood in inducing output that is high in creative quality. ${ }^{4}$ Consistent with this reasoning, we propose the following hypothesis:

HYPOTHESIS 1. A positive mood compared to a negative mood leads to more highly creative output for fixed compensation, but not for quantity-dependent and creativity-dependent compensation.

\footnotetext{
${ }^{4}$ Cognitive evaluation theory (Ryan 1982; Ryan and Deci 2000) proposes that the imposition of extrinsic rewards, such as performance-dependent financial incentives, may change one's focus or underlying motivation from what it would be in the absence of such extrinsic rewards. In particular, when extrinsic rewards are constraining, they will have a negative impact on the desired performance rather than an additive effect that facilitates the desired performance. Performance-dependent compensation may pose such a constraint on intrinsic motivation to create highly creative output. However, we do not base our predictions on cognitive evaluation theory because the theory underlying the effects of mood on creativity focuses on differential information processing strategies, not on variation in intrinsic motivation for creativity.
} 


\section{The interactive effects of negative mood and compensation on low-creativity output}

As explained in the prior sections, in comparison to positive mood, a negative mood does not lead to a state of relaxed playfulness or broad conceptual focus. Thus, a negative mood makes retrieval of information from memory more difficult and constrains one's ability to generate ideas that are considered to be of high creative quality. Further, a negative mood induces an effortful and systematic processing strategy (Schwarz and Bless 1991). This effortful approach is a result of the discontent one feels when in a negative mood. A negative mood is a signal to the brain that something is wrong and that something must be done to alleviate the undesirable feelings one experiences when in a negative mood (Schwarz 1990; Dru et al. 2008). Stated differently, negative mood induces a processing strategy of urgency. The effortful strategy evoked by negative mood is unlikely to translate into output that is of high creative quality, since negative mood restricts one's perceptual view. However, an effortful strategy is capable of impacting the quantity of output that one produces, but this quantity is likely to be of low creative quality.

Prior accounting research on performance-dependent compensation indicates that effort does not translate into increased ability to generate highly creative output in one-round settings, but quantity-dependent incentives are effective in increasing the quantity of output produced by individuals in creative tasks (e.g., Kachelmeier et al. 2008). A quantity-dependent incentive, therefore, is likely to be additive to the effects of negative mood on effortful focus predicted by theory. Thus, when combined with negative mood, quantity-dependent compensation will exacerbate the likelihood that individuals will exert effort to produce output, and that output will be of low creative quality.

Creativity-dependent compensation also motivates participants to put forth effort. 
However, unlike quantity-dependent incentives, creativity-dependent incentives shift focus from the quantity of output to the quality of output. However, this focus on high creative quality is inhibited by the effects of negative mood as predicted by theory (i.e., negative mood leads to a narrowed cognitive focus that hinders creative ability). However, since negative mood hinders creative quality, effortful actions in these circumstances may be prolonged due to the inability to meet creative performance targets with initial efforts. In other words, individuals in a negative mood who have creativity-dependent incentives will not be satisfied with the production of lowquality creative output and will therefore exert continued effort in an attempt to produce output that is of higher creative quality. We expect participants in a negative mood who operate under creativity-dependent compensation to produce output that is higher in creativity than what is produced by the negative mood, quantity-dependent compensation group. However, we expect this output to consist of a larger number of low-to-medium creativity puzzles compared to their positive mood counterparts.

Taken together, we predict that individuals in a negative mood with quantity-dependent compensation will produce a higher quantity of output that is of low creative quality (i.e., lowcreativity output) than individuals with fixed or creativity-dependent compensation. This leads to the following hypothesis:

HYPOTHESIS 2. When individuals are in a negative mood, quantity-dependent compensation leads to a higher quantity of low-creativity output compared to fixed and creativity-dependent incentives.

\section{Method}

\section{Participants}

We recruited 109 student participants from a large university in the Southeast region of the United States to participate in a single-round laboratory experiment. We conducted 12 
experimental sessions, and each session lasted approximately 45 minutes. The number of participants per session varied from 7 to 11 . Fifty-four percent of participants were female, and the average age of all participants was 22 years. Participants had 3.5 years of work experience on average. Participants completed the experiment entirely using paper-based materials. All experimental procedures were approved prior to data collection by the authors' Institutional Review Board.

\section{Experimental procedures}

We adopt the rebus puzzle creativity task portion of our experimental procedures from Kachelmeier et al. (2008). In addition to offering comparability to previous experimental studies that examine the effect of incentives on creativity, rebus puzzles allow us to examine the effect of mood on a multi-dimensional creativity task, which is an understudied area in the broader mood and creativity literature.

Figure 1 presents an outline of the experimental procedures. Participants begin by reading a set of instructions that describes the experimental task and includes illustrative examples of rebus puzzles, which are defined as "a kind of riddle in which words and/or diagrams are used to represent a popular expression or phrase." Participants then read a description of the compensation scheme to which they are randomly assigned. Participants then answer two comprehension check questions in order to demonstrate their understanding of how their payment would be calculated. The experimenters examine all participant responses and ensure that any misunderstandings are corrected before proceeding. Next, the first phase of the multidimensional mood induction process (explained in detail in the following section) is implemented with an audio recording and visual presentation Participants then create rebus

puzzles for 20 minutes while the mood induction process continues through the use of mood 
inducing classical background music. ${ }^{5}$ After participants finish the 20-minute rebus puzzles task, they complete a post-experimental questionnaire and provide demographic information. Before participants leave the room, an experimenter concludes the session with debriefing statements to ensure participants are no longer influenced by the study's mood induction procedures.

$$
\text { [Insert Figure } 1 \text { here] }
$$

\section{Independent variables}

We employ a 2 X 3 between-subjects full-factorial design, where we manipulate participants' mood and compensation scheme.

\section{Mood manipulation}

For the first independent variable, mood, we developed a mood induction process consisting of audio and visual stimuli that is designed to manipulate participants' mood to either be relatively more positive or more negative (hereafter simply referred to as positive and negative mood). We first describe the pretest used to validate the mood induction process and then provide a detailed description of the process used in the experimental manipulation.

Validation of mood induction procedures. Several weeks before the experiment, we conducted positive and negative mood validation sessions wherein a total of 39 participants went through the mood induction process. Participants were recruited from the same student population, sessions were held in the same location, and the setup of the room was the same as in

\footnotetext{
${ }^{5}$ We note that mood-influencing factors may be present, such as affective reactions to the creative tasks (Amabile, Barsade, Mueller, and Staw 2005) and to the presence of monetary incentives (Meloy, Russo, and Miller 2006). Importantly, these factors are constant across treatment groups, and therefore do not detract from conclusions drawn about differences between treatment groups. Further, an important design feature in this study is that the mood induction process takes place after participants are instructed and quizzed over the creative task and compensation instructions. Thus, any affective reactions to the content of the instructions (including details of monetary incentives) occur prior to the mood induction process rather than being introduced as a potentially conflicting influence after the mood induction process that might serve to negate the effectiveness of the mood manipulation.
} 
the main experiment. ${ }^{6}$

Rather than creating rebus puzzles, pretest participants responded to the modified positive and negative affect scale (PANAS; Watson et al. 1988) and answered an exit questionnaire. The PANAS scale is a commonly accepted means of measuring mood states in accounting research (e.g., Sawers 2005; Cianci and Bierstaker 2009; Johnson et al. 2016). It consists of 20 words that describe different mood states, ten words for positive mood states and ten words for negative mood states. Participants are asked to rate on a scale of 1 (Very Slightly) to 5 (Extremely) the extent to which they feel this way right now. Afterwards, the positive and negative items are summed, to create positive and negative mood scores. Statistical analyses indicate that participants who completed the positive mood induction procedure had a significantly higher positive mood score than those in the negative mood treatment group $(t=2.13, p=0.02$, onetailed). Participants who completed the negative mood induction procedure had a significantly higher negative mood score than those in the positive mood treatment group $(t=3.23, p<0.01$, one-tailed). Hence, results from our pretest validate that our mood induction process induced the desired mood states in participants.

Mood induction procedures. In the main experiment, the mood induction process begins after experimenters examine participants' responses to comprehension checks over the rebus puzzle task compensation instructions. The mood induction process consists of complementary visual and audio stimuli. First, all participants are asked to physically turn to face a 70 -inch television in the front of the room and read all statements as they appear on the screen and are read aloud. Then a slideshow begins playing either the positive or negative versions of

\footnotetext{
${ }^{6}$ While we preclude students from participating in both the validation session and the main study, the demographic composition of the samples is qualitatively identical. As participants for the validation session were recruited from the same population pool as participants from the full study, we are confident that our pretest results generalize to participants in the full study.
} 
Velten's Mood Statements (Velten 1968). These statements are commonly used in mood induction research and have been found to have a high level of internal consistency (e.g., Jennings et al. 2000; Cianci and Bierstaker 2009). They are an especially appropriate mood induction technique for our study, as they are devoid of any images or video which may confound participants' rebus puzzle ideas. Velten's Mood Statements consist of 60 statements for positive mood induction and 60 statements for negative mood induction. The statements start with a mood-neutral statement and become increasingly positive or negative. ${ }^{7}$

To create a repeatable high-quality experience across participant groups, we hired a professional voice actress to record a voiceover of each of Velten's Mood Statements. ${ }^{8}$ The positive mood statements were read in a positive-tone voice, and the negative mood statements were read in a negative-tone voice. The voice recordings were synced with the slideshow, so participants heard the recording of a statement as it was displayed on the 70-inch television screen. Specifically, the statements appear on the screen one at a time and are displayed for an average of five seconds each while the voice actress read them aloud, resulting in a total slideshow length of approximately five minutes. ${ }^{9}$

The other component of the mood induction process is the strategic use of background music throughout the rebus puzzle creation task. Specifically, immediately following the mood induction statements, participants are directed to turn to back to their tables to begin the production of rebus puzzles, and we simultaneously we begin to play positive or negative mood

\footnotetext{
${ }^{7}$ We adjusted the thirteenth negative Velten mood statement from, "I'm afraid the war in Vietnam may get a lot worse", to, "I'm afraid world conditions may get a lot worse." All other statements appear in their original form. ${ }^{8}$ The professional voice actress used in our study was hired through the website www.fiverr.com, a website used to hire freelance independent contractors for various business services. Our voice actress had over 5,000 five-star reviews and was distinguished as a top-rated voice actress.

${ }^{9}$ The mood statement presentation was designed so that the majority of the statements appeared on the screen for five seconds to give participants sufficient time to process each statement. However, some lengthier statements remained on the screen for as long as eight seconds.
} 
induction music in the background. For the positive mood induction, we played "Coppelia Act I, Valse," and for the negative mood induction, we played "Russia Under the Mongolian Yoke", which are two of the most prevalently implemented songs for mood induction (Västfjäll 2002).

Two key features of a song are essential to its ability to serve as a mood induction procedure: its key and its tempo. Music used for positive mood induction is performed in a major key and has beats per minute (bpm) greater than 100, while music used for negative mood induction is performed in a minor key and has a bpm less than 80 . The music is played for the entire 20 minutes of the rebus puzzles task. ${ }^{10}$

\section{Compensation manipulation}

All participants earn a $\$ 5$ fee for showing up on time for the experimental session. The second independent variable, compensation scheme, was the compensation participants could earn in addition to the show-up fee for participating in the experimental task. Compensation scheme is manipulated at three levels: fixed, quantity-dependent, and creativity-dependent. Participants in the fixed compensation scheme learn that they will be paid $\$ 25$ for participating in the experiment regardless of the quantity, or creativity, of puzzles they produce. Specifically, they are told, "You will get $\$ 25$ no matter what you do."

Participants in the quantity-dependent compensation scheme learn that their compensation is based on how many puzzles they can construct in 20 minutes. The instructions note that the participant who produces the greatest number of puzzles in this version of the research will receive $\$ 45$, while the participant who produces the least number of puzzles will

\footnotetext{
${ }^{10}$ Prior studies estimate that the least amount of time one can expect a mood induction procedure to hold is 20 minutes. The post-instruction rebus puzzle task is 20 minutes. The joint use of Velten's Mood Statements and background music creates a mood induction process that should stimulate a mood that persists for the duration of the experimental session. First, we deliberately arranged the instructional materials so there would be as little time as possible between the end of the presentation of Velten's Mood Statements and the start of the creativity task. Second, the classical background music is played throughout the 20 -minute rebus puzzle task to prevent premature expiration of the desired mood states.
} 
receive $\$ 5$. Everyone else will receive between $\$ 45$ and $\$ 5$ to result in an average payment of $\$ 25$.

Participants in the creativity-dependent compensation scheme learn that their compensation is based on how creative their most creative puzzle is. ${ }^{11}$ Specifically, their compensation is based on the creativity rating of the highest rated puzzle, disregarding the creativity ratings of any lower rated puzzles. The participant whose puzzle has the highest creativity rating average in this version of the research will receive $\$ 45$, and the participant whose puzzle has the lowest creativity rating average will receive $\$ 5$. Everyone else will receive between $\$ 45$ and $\$ 5$, to result in an average payment of $\$ 25$.

Importantly, consistent with prior studies, we hold constant the average compensation among treatment groups, while varying the nature of the compensation. Also, the average compensation of $\$ 25$ is consistent with the incentives used in the extant literature (Kachelmeier et al. 2008; Kachelmeier and Williamson 2010; Kachelmeier et al. 2019).

\section{Rating procedure}

In order to calculate the rebus puzzles' creativity scores, a panel of seven independent raters who were blind to the study's purpose and hypotheses rated each rebus puzzle for its creativity. The panel rated the puzzles on a scale of 1-10 in a single rating session. The raters were a mix of graduate students and adults from the community. The raters received a fixed compensation of $\$ 125$ each. The rating session lasted approximately four hours and included tenminute breaks every hour and a lunch break. Raters were seated at separate computer stations

\footnotetext{
${ }^{11}$ We use a different form of creativity-only incentive compared to Kachelmeier et al. (2008). Our incentive setting more clearly encourages creative output by explicitly basing compensation on the most creative puzzle instead of the average of all puzzles produced. A creativity-only incentive which is based on the average creativity rating of all puzzles contains a denominator effect, where participants must weigh benefit of producing a very unique puzzle with the cost that this puzzle increases the denominator, and thus may lower their overall average. Our design choice does not punish the production of risky and potentially very innovative output. Brink et al. (2020) uses this manipulation and does not observe any differences in output compared to Kachelmeier et al. (2008).
} 
and were instructed not to talk during the rating session. The order of the puzzles was randomized prior to the rating session, and each rater saw the puzzles in the same order. We utilized z-tree software for the rating session (Fischbacher 2007). Prior to the rating session, the raters and an experimenter reviewed the same instructions given to participants in the main study, except for the portion of the instructions explaining participants' compensation.

The Cronbach's Alpha, a measure for inter-rater reliability, for the ratings of all seven raters is 0.66, which prior studies have noted is in the acceptable cutoff range (DeVellis 1991). To test the robustness of our results, we repeat our analyses with a creativity score that is calculated after we drop the two raters who have the lowest correlation with the panel's average. This is similar to the procedure used in Kachelmeier et al. (2008), and it is used to control for the possibility that outlier raters may be driving the results. Our Cronbach's Alpha for the remaining panel of five raters is 0.68 , and all of the main results hold with this subset of raters. All subsequent analyses in this paper report results using ratings from all seven raters. ${ }^{12}$

\section{Results}

Prior to hypothesis testing, we establish consistencies with overarching patterns observed in prior accounting studies that investigate creativity (Kachelmeier et al. 2008; Kachelmeier and Williamson 2010; Kachelmeier et al. 2019). First, we find incentives for creativity do not lead to superior highest creativity (i.e., the most creative puzzle) compared to quantity incentives and fixed incentives for positive $\operatorname{mood}\left(F_{2,55}=2.11, p=0.131\right)$ and negative $\operatorname{mood}\left(F_{2,54}=1.58, p\right.$ $=0.217)$. Second, we find quantity-dependent incentives lead to the largest number of puzzles $(F$

\footnotetext{
${ }^{12}$ We examine how comparable our panel's creativity ratings are to a different panel's creativity ratings from a prior study that replicates key performance measures of Kachelmeier et al. (2008). To do so, we obtain an identical block of 50 rebus puzzles that was used in a prior study. Then we compare our panel's creativity ratings for this block of 50 rebus puzzles to the ratings given by the panel in the previous study. Results indicate that the current raters' creativity ratings have a high level of consistency with those of prior studies, providing assurance that our results are not due to differences between our raters and those of previous studies.
} 
$2,109=11.35, p<0.001)$ and the highest total creativity $\left(F_{2,109}=6.40, p=0.002\right)$ compared to fixed and creativity-dependent incentives.

\section{Tests of Hypothesis 1}

Hypothesis 1 predicts a positive effect of mood on highly creative output for fixed compensation, but not for quantity-dependent and creativity-dependent compensation. We define highly creative output consistent with Kachelmeier et al. (2008) as the highest quartile of creativity ratings. Specifically, we define highly creative output as rebus puzzles with an average creativity rating greater than or equal to 5.5. Figure 2 presents information about the quartile cutoffs and presents representative examples of puzzles submitted by participants.

[Insert Figure 2 here]

Table 1, Panel A presents descriptive statistics for highly creative output by cell, and Figure 3 presents this information visually. The highest average highly creative output is 4.79 in the fixed compensation with positive mood cell. The lowest average highly creative output is 2.94 in the quantity-dependent compensation with negative mood cell. ANOVA results are presented in Table 1, Panel B for completeness. Consistent with prior research which suggests a positive mood leads to a state of relaxed playfulness conducive to producing highly creative output, the main effect of $\operatorname{mood}$ is significant $(F=2.98, p=0.044$, one-tailed).

H1 predicts an interaction effect between mood and compensation, such that performance-dependent compensation crowds-out the relaxed playfulness attributed to positive mood. To test our hypothesis, we use a coded contrast. ${ }^{13}$ We use as contrast weights 3 (fixed, positive mood), -1 (fixed, negative mood), 0 (quantity-dependent, positive mood), -1 (quantity-

\footnotetext{
${ }^{13}$ We use a coded contrast rather than an ANOVA to test our hypothesis, because an ANOVA assigns contrast weights that predict a disordinal interaction, which is not appropriate for our setting, since we predict an ordinal interaction. Consistent with prior literature we use a coded contrast to test an ordinal interaction. Unless otherwise noted, the $p$-values reported in this section are one-tailed consistent with our theoretical development.
} 
dependent, negative mood), 0 (creativity-dependent, positive mood), and -1 (creativitydependent, negative mood). ${ }^{14}$ Table 1 , Panel C, provides the result of the contrast, which is statistically significant $(F=5.18, p=0.013) .{ }^{15}$ We use pairwise comparisons to test our directional predictions for creative output under positive versus negative mood within each compensation condition (Table 1, Panel D). Our results show that this difference is statistically significant for the fixed condition $(t=1.78, p=0.042)$, but not for quantity-dependent incentives $(t=0.65, p=0.260)$, or for creativity-dependent $(t=0.68, p=0.252) .{ }^{16}$ These findings provide support for Hypothesis 1, which predicts that performance-dependent compensation will crowd out the effects of positive mood on the creation of highly creative output.

[Insert Table 1 and Figure 3 here]

\section{Supplemental analyses: $\mathrm{H} 1$}

Test of a moderated mediation model of relaxed playfulness and compensation pressure

\footnotetext{
${ }^{14}$ With these contrast codes, we allow for both a main effect of mood on highly creative output, and an interactive effect of mood and compensation on highly creative output (H1). Specifically, these weights predict more highly creative output from participants in the positive mood condition, as the contrast coefficient for Cell $1(+3)$, Cell 3 $(0)$, and Cell $5(0)$ are greater than that for Cell $2(-1)$, Cell $4(-1)$, and Cell $6(-1)$. Given that we expect participants in the negative mood condition will not experience an increase in their state of relaxed playfulness they then have less of an opportunity for compensation pressure to crowd-out the creativity facilitating information processing strategies adopted by participants in the positive mood condition. As such, the weights specify no difference in the contrast coefficient for highly creative output across compensation schemes in the negative mood condition Cells 2 , 4 , and 6 all =-1). In addition, the contrast coefficient is significantly greater for the positive mood participants who receive fixed compensation than for the negative mood participants who receive fixed compensation, but not for the other conditions, (Cell $1(+3)$ is significantly greater than that for Cell $2(-1)$, but not for Cell $3(0)$ and Cell $4(-1)$ or Cell $5(0)$ and Cell $6(-1))$, reflecting the specified interaction.

15 The Guggenmos et al. (2018) three-part contrast analysis approach suggests the planned contrast captures the variance in the data well. A visual inspection confirms a good fit between the observed data and the predicted pattern implied by the contrast weights. The proportion of between-cells variance left unexplained by the contrast is low $\left(q^{2}=2.88 \%\right)$, and the between-cells residual variance is not significant $\left(F_{4,103}=0.04, p=0.996\right)$. This suggests that our planned contrast captures the variance in the data well.

${ }^{16}$ We also examine the potential motivational crowding-out effect of incentives on creative output by comparing the mean coefficient of participants in the fixed-positive mood treatment to those in the creativity-dependent-positive mood treatment. These means are 4.79 for fixed-positive and 3.58 for creativity-dependent-positive $(t=1.45, p=$ 0.078 , one-tailed). We do not see a statistically significant difference in the number of highly creative cards when comparing the fixed and positive mood cell with the quantity-dependent and positive mood cell $(t=0.98, p=0.167$, one-tailed). While this test is not a focal point of our analysis, it nevertheless provides an interesting result, because it shows that incentives for creativity lead to less highly creative output compared to the absence of such incentives.
} 
Given that prior research suggests being in a state of relaxed playfulness has a profound impact on information processing strategies which are conducive to producing highly creative output and the effect of compensation on relaxed playfulness, this section examines the extent to which relaxed playfulness and compensation pressure are mechanisms driving the effect of positive mood on highly creative output. ${ }^{17}$ Figure 4 presents our theoretical model.

\section{[Insert Figure 4 here]}

Our theoretical model predicts that the positive mood main effect on highly creative output is mediated by its effect on one's state of relaxed playfulness. Furthermore, consistent with the theoretical arguments set forth in this paper, we predict that compensation pressure moderates the positive mood and relaxed playfulness relation. Both predictions lead to a mediated moderation model, which we test using Hayes (2013), PROCESS macro in SPSS (Model 7). Figure 5 presents our results.

Results indicate that a positive mood has a significant positive effect on one's state of relaxed playfulness $(t=2.52 ; p=0.007)$, and this relation is negatively moderated by compensation pressure $(t=-2.12 ; p=0.018)$. We also find that a state of relaxed playfulness has a significant positive effect on the amount of highly creative output one generates $(t=2.28 ; p=$ 0.012). Finally, in a model which includes relaxed playfulness, positive mood's main effect on highly creative output falls below conventional levels of significance $(t=1.54 ; p=0.064)$. Indicating that the effect of a positive mood on highly creative output is partially mediated by its

\footnotetext{
${ }^{17}$ We measure Relaxed Playfulness as the sum of two questions in which participants rated their agreement on a seven-point Likert scale to the following statements: "I was nervous about my ability to construct rebus puzzles," (reverse coded), and "I had the freedom to adopt my own approach to construct rebus puzzles," where 1 = Strongly Disagree and $7=$ Strongly Agree. Compensation Pressure is measured as the sum of two questions in which participants rated their agreement on a seven-point Likert scale to the following statements: "I focused on enjoying the task without consideration of the impact of my decisions on my compensation" (reverse coded), and "Thinking about my compensation interfered with my ability to concentrate on creating rebus puzzles," where $1=$ Strongly Disagree and $7=$ Strongly Agree.
} 
effect on one's state of relaxed playfulness. In summary, these findings provide support for our proposed crowding out effect.

\section{[Insert Figure 5 here]}

\section{Analysis of creativity over time}

To determine if the crowding-out effects observed in Hypothesis 1 occur immediately or gradually, we examine the creativity of output produced by participants over time. For the positive mood treatments, we examine the pattern of highly creative output across time between contract type (see Figure 6). Consistent with the crowding out of positive mood documented in other analyses, Figure 6 illustrates that for positive mood participants, those in the fixed compensation group continue to produce highly creative puzzles longer than participants subject to performance-contingent compensation. This is consistent with our prediction that performance-dependent compensation gradually diminishes the relaxed playfulness induced by positive mood, which leads to a narrower conceptual focus and dampens the effect of positive mood on creative quality during the latter part of the production task. Specifically, the fixed wage, quantity-dependent, and creativity-dependent schemes are nearly identical in their highcreativity production for the first few puzzles produced. At approximately the seventh card, the quantity-dependent scheme diverges from the fixed and creativity-dependent schemes, such that participants in this group are producing additional high-creativity output at a slower rate. In the creativity-dependent scheme, this decline occurs at approximately the tenth card produced.

\section{[Insert Figure 6 here]}

This analysis allows for the comparison of the effect of mood on initial creativity with the effect of mood throughout the experiment. ${ }^{18}$ Positive mood initially appears to have a positive

\footnotetext{
${ }^{18}$ We find, on average, higher total creativity for the initial production of cards when mood is positive compared to negative across all compensation conditions. We conduct an ANOVA with total creativity first $25 \%$ of cards as the
} 
effect across compensation conditions, as it leads to superior creativity ratings for the $25 \%$ of

cards produced. However, over the entire 20-minute duration, performance-dependent

compensation crowds out the mood manipulation. This indicates that the crowding-out effect is

not instantaneous, but rather appears to occur after time passes. This, in turn, indicates that the

motivation that results from performance-dependent compensation effects the motivation from

mood.

Crowding out for total creativity and most creative card

Similar to our approach for highly creative cards, we use planned contrast tests to examine a crowding-out effect for total creativity (i.e., sum of ratings for all cards produced by a participant). Table 2 reports the results of analyses of total creativity. On average, the difference in total creativity between positive and negative mood is larger in the fixed condition compared to performance-dependent incentives. Table 2, Panel B reports the contrast test for total creativity with weights $2,0,2,2,-3$, and -3 , which is statistically significant $(F=13.00, p<$ 0.001, one-tailed). ${ }^{19} \mathrm{We}$ use pairwise comparisons tests of our directional predictions to examine

dependent variable and compensation and mood as independent variables. We find a statistically significant main effect of compensation $(F=54.84, p=0.001)$ and $\operatorname{mood}(F=6.027, p=0.016)$. Importantly, in follow-up pairwise comparisons tests, we observe a significant difference between the total creativity of the positive and negative treatment groups across all compensation conditions. The difference in total creativity of the first $25 \%$ of cards produced for the fixed-positive condition compared to the fixed-negative condition is significant $(t=1.444, p=$ 0.079). The difference in total creativity of the first $25 \%$ of cards produced for the quantity-positive condition compared to the quantity-negative condition is significant $(t=1.396, p=0.086)$, and the difference in total creativity of the first $25 \%$ of cards produced for the creativity-positive condition compared to the creativity-negative condition is significant $(t=1.422, p=0.082)$. Recall that similar tests for total creativity of the entire production of cards only indicated a significant difference for the fixed-positive condition compared to the fixed-negative condition. In sum, we observe a significant difference between the total creativity of initial production across contract type, whereas for the total creativity of the entire production of cards, this result is only observed for the fixed compensation condition. This indicates that the crowding-out effect of compensation on mood occurs over time. While this supplemental analysis of the first $25 \%$ of cards produced is an imperfect substitute to measuring creativity over time, it nevertheless is informative in that it allows for an assessment of initial creativity.

${ }^{19}$ The contrast weights used reflect both the crowding out prediction and, similar to Hypothesis 2, the prediction that negative mood leads to higher quantity, which will affect total creativity. The Guggenmos et al. (2018) three-part contrast analysis approach suggests the planned contrast captures the variance in the data well. A visual inspection confirms a good fit between the observed data and the predicted pattern implied by the contrast weights. The proportion of between-cells variance left unexplained by the contrast is low $\left(q^{2}=6.56 \%\right)$, and the between-cells residual variance is not significant $\left(F_{4,103}=0.23, p=0.922\right)$. 
differences in total creativity for positive and negative mood by compensation condition. We find a marginally significant difference for fixed compensation ( $t=1.35, p=0.093$, one-tailed), but not for quantity-dependent $(t=0.22, p=0.414$, one-tailed), or creativity-dependent $(t=$ $0.35, p=0.365$, one-tailed).

[Insert Table 2 here]

Next, we examine a crowding out for the most creative card produced (i.e., highest rated card). Table 3 reports the results. On average, the difference in the rating for the most creative card between positive and negative mood is larger in the fixed condition compared to performance-dependent incentives. We analyze differences using coded contrasts (Table 3, Panel B) followed by pairwise comparisons (Table 3, Panel C). We use as contrast weights 2, $-2,-2,-2$, 2, and 2. The contrast is statistically significant $\left(F=7.67, p=0.004\right.$, one-tailed). ${ }^{20}$ Pairwise comparisons comparing the rating for positive and negative mood by compensation type finds a significant difference for fixed compensation ( $t=1.75, p=0.044$, one-tailed), but not for quantity-dependent $(t=0.22, p=0.414$, one-tailed $)$, or creativity-dependent $(t=0.03, p=$ 0.487 , one-tailed).

\section{[Insert Table 3 here]}

In summary, these results indicate that the proposed positive crowding-out effect carries over to other dimensions of creative output, which provides additional support for the reasoning put forward in Hypothesis 1.

\footnotetext{
${ }^{20}$ The contrast weights used for this analysis differ from the previous analysis. For this analysis, most creative card is only predicted to be affected by the compensation scheme, not quantity as was the case for total creativity in the previous analysis. The Guggenmos et al. (2018) three-part contrast analysis approach suggests the planned contrast captures the variance in the data well. A visual inspection confirms a good fit between the observed data and the predicted pattern implied by the contrast weights. The proportion of between-cells variance left unexplained by the contrast is low $\left(q^{2}=11.25 \%\right)$, and the between-cells residual variance is not significant $\left(F_{4,103}=0.24, p=0.913\right)$.
} 


\section{Tests of Hypothesis 2}

Hypothesis 2 predicts that negative mood and quantity-dependent compensation will lead to a greater quantity of low-quality creative output than other treatment conditions. We test Hypothesis 2 by comparing participants' low-creativity output, defined as output that falls in the lowest quartile of creativity ratings. Table 4, Panel A provides descriptive statistics. On average, participants in the negative mood condition with quantity-dependent incentives produce the largest number of low-creativity cards. We use a coded contrast with weights $1,1,1,-5,1$ and 1 with the number of low-creativity puzzles as dependent variable to test this pattern of results. The contrast is statistically significant ( $F=20.41, p<0.001$, one-tailed) (Table 4, Panel B). ${ }^{21}$ Pairwise comparisons of our directional prediction of low-creativity output for positive and negative mood by compensation condition (see Panel C of Table 4) indicate that the difference between mood conditions is statistically significant for quantity-dependent $(t=-1.71, p=0.048$, one-tailed), but not for fixed ( $t=0.931, p=0.179$, one-tailed) or creativity-dependent ( $t=$ $1.212, p=0.117$, one-tailed) compensation. Figure 7 illustrates the observed pattern of results for low-creativity output. ${ }^{22}$

\section{[Insert Table 4 and Figure 7 here]}

We also analyze the scores of lowest creativity (i.e., participants' lowest rated puzzle) to test the pattern predicted by Hypothesis 2. Table 5, Panel A provides descriptive statistics. We use a coded contrast with weights $1,1,1,-5,1$ and 1 with the creativity score of the lowest rated

\footnotetext{
21 The Guggenmos et al. (2018) three-part contrast analysis approach suggests the planned contrast captures the variance in the data well. A visual inspection confirms a good fit between the observed data and the predicted pattern implied by the contrast weights. The proportion of between-cells variance left unexplained by the contrast is low $\left(q^{2}=21.28 \%\right)$, and the between-cells residual variance is not significant $\left(F_{4,103}=1.38, p=0.246\right)$.

${ }^{22}$ Corroborating the additive effect of quantity-dependent incentives on negative mood, we use a coded contrast with weights $-1,-1,-1,5,-1,-1$ to test that the quantity-dependent negative mood condition produces significantly more output that is modeled after an example in the instructions than all other treatment conditions. The contrast is statistically significant $\left(F_{4,103}=7.86, p=0.006\right)$. Prior research has shown that such output is inversely related to creativity ratings (Kachelmeier et al. 2008).
} 
puzzle as dependent variable. The contrast is statistically significant $(F=6.74, p=0.006$, onetailed) (Table 5, Panel B). ${ }^{23}$ Pairwise comparisons of our directional predictions (Table 5, Panel C) indicate that the difference is statistically significant for quantity-dependent incentives $(t=$ $2.05, p=0.024$, one-tailed $)$, but not for fixed $(t=-0.63, p=0.268$, one-tailed $)$ or creativitydependent ( $t=0.46, p=0.326$, one-tailed). In summary, the results support our second hypothesis.

[Insert Table 5 here]

The theoretical development for Hypothesis 2 suggests a higher quantity of low-tomedium creativity puzzles for creativity-dependent incentives when mood is negative compared to when mood is positive. We examine, consistent with our theorical development, the bottom $50 \%$ of creative puzzles for positive and negative mood for creativity-dependent compensation. In an untabulated analysis, we find participants in the negative mood creativity-dependent treatment group produce significantly more low-creativity output, defined as output in the bottom $50 \%$, than participants in the positive mood creativity-dependent treatment group $(t=-1.38, p=$ 0.088 , one-tailed). Such a difference in low-creativity output does not exist between the negativefixed and the positive-fixed treatment group $(t=0.58, p=0.282$, one-tailed $)$ or quantitydependent $(t=-1.26, p=0.108$, one-tailed $)$.

In summary, our results are consistent with performance-dependent incentives leading to more focused effort, and negative mood directing this effort toward the production of lowcreativity output. Low-creativity output can be costly to firms, because firms must screen

\footnotetext{
23 The Guggenmos et al. (2018) three-part contrast analysis approach suggests the planned contrast captures the variance in the data well. A visual inspection confirms a good fit between the observed data and the predicted pattern implied by the contrast weights. The proportion of between-cells variance left unexplained by the contrast is low $\left(q^{2}=9.60 \%\right)$, and the between-cells residual variance is not significant $\left(F_{4,103}=0.18, p=0.949\right)$.
} 
employee output for high- and low-creativity output. Such a screening process can be inherently timely and costly with more low-creativity output leading to greater costs. So, companies who pay performance-dependent compensation and where low creativity output has no marginal value may consider instituting mood-improving initiatives, not to increase the production of high-creativity output, but rather to limit the production of low-creativity output.

\section{Conclusion}

Creativity is the lifeblood of the information-age economy. While research in accounting has examined different facets of creativity, the interactive effects of compensation schemes and mood on creative output have thus far not received any consideration. However, given the resources that are invested in mood improvement initiatives in practice and the importance of creativity for companies, we consider this an important research question.

The effect of mood on creativity has received widespread attention in the psychology and management literature without reaching conclusive findings. A number of studies find that positive mood leads to higher creativity, while negative mood leads to a greater focus on quantity (Schooler et al. 1993; Finke 1996; Simonton 1997; Dietrich 2004). We build on this research by drawing from theory to make theoretical predictions about the interactive effects of mood and performance-dependent compensation on the quality and quantity of output in a creative task.

We find support for our hypotheses. A positive mood compared to a negative mood leads to more production of output that is higher in creative quality for fixed compensation, but not for quantity-dependent and creativity-dependent incentives. In addition, we find that negative mood facilitates the production of a higher quantity of output of lower creative quality than positive mood. In particular, we find a larger number of low-creativity puzzles (i.e., lowest $25 \%$ of creativity) in the quantity-dependent and negative mood cell compared to quantity-dependent 
compensation and positive mood and a larger number of low-to-medium creativity (i.e., lowest $50 \%$ of creativity) output in the creativity-dependent and negative mood cell compared to creativity-dependent and positive mood.

Our findings extend research on the effect of mood on creativity. First, we show that the effect of mood on creativity varies with form of compensation and time horizon. For instance, positive mood effects creativity for fixed compensation, but not for quantity-dependent and creativity-dependent incentives. Among performance-dependent incentives, negative mood has the effect of generating a higher quantity of low-creativity output, which is exacerbated by performance-dependent compensation. In addition, we find an initial effect of positive mood across all conditions, but this effect is crowded out over time when compensation is based on performance. We contend that this "crowding-out" is due to the fact that performance-dependent compensation gradually leads to the deterioration of the relaxed playfulness induced by positive mood. Identifying factors that moderate the effect of mood on creativity contributes to reconciling contradictory findings on the effect of mood on creativity in research.

Second, we contribute to the accounting research on creativity. The overwhelming majority of laboratory studies in accounting shows a superiority of quantity-dependent incentives over other forms of compensation (Kachelmeier et al. 2008; Kachelmeier and Williamson 2010; Kachelmeier et al. 2019). We show that negative mood leads to additional low-creativity output for quantity-dependent incentives. Low-creativity output in many settings could be undesirable because it can lead to costs in identifying and disposing of low creativity ideas. This finding has implications for the design of compensation schemes in practice. Specifically, companies that rely on insights from accounting research and use quantity-dependent incentives to incentivize 
creativity need to consider the prevailing mood among their workforce, because a negative mood could potentially lead to a cost related to low-creativity output.

Lastly, our findings help to reconcile contradictory findings in the psychology and accounting literature. A number of studies in the psychology literature find a negative effect of performance-dependent incentives on creativity compared to the absence of performancedependent incentives. These studies commonly rely on student participants in school settings and provide limited performance-dependent incentives (Amabile 1982; Amabile et al. 1990). ${ }^{24}$ In comparison, studies on creativity in accounting commonly do not find a negative effect of performance-dependent incentives on creativity compared to the absence of such incentives (Kachelmeier et al. 2008; Kachelmeier and Williamson 2010; Kachelmeier et al. 2019). However, these accounting studies use the rigor of experimental economics with laboratory settings and financial incentives as motivation to participate (commonly, \$25 on average; Kachelmeier et al. 2008; Kachelmeier and Williamson 2010; Kachelmeier et al. 2019). Our findings provide a potential causal link that helps to reconcile these contradictory findings. Studies in psychology that use students either in school or college settings with minimal incentives are likely to rely on inducing some positive emotion to get individuals to participate and exert effort, while such a hype factor is not necessary and therefore less likely to be a determining factor for participating in accounting studies given the use of financial incentives. We show a negative effect of creativity incentives on creativity when mood is higher, but we do not find such an effect when mood is lower. This moderating effect of mood on the effect of performance-dependent compensation could potentially reconcile the contradictory findings in

\footnotetext{
${ }^{24}$ For example, many studies in the psychology and management literature define incentives as desirable activities, praise, or recognition (Byron and Khazanchi 2012).
} 
research in psychology and accounting on the effect of performance-dependent incentives on creativity.

Our findings provide opportunities for future research. For example, our performancedependent incentives are monetary, which activates a monetary mental frame and reference point. Research on the effect of non-financial rewards proposes that non-monetary rewards activate a different mental frame (Presslee et al. 2013). It is possible that our findings about the crowding-out effect of monetary incentives on positive mood do not translate to non-monetary incentives. In addition, we manipulate mood to be relatively more positive or more negative, but given the comparatively low stakes in a laboratory study, we cannot infer from our manipulation that our negative mood manipulation induces a mood that would be considered low or negative in the overall spectrum of possible mood states (e.g., our induced negative mood is not likely comparable to the negative moods an individual would experience in situations such as physical or mental illness or when undergoing a crisis). Research in psychology indicates that very low moods brought about by existential fears activate survival instincts (Friedman et al. 2007). This research indicates that very low moods could potentially lead to higher creativity. It is unlikely that companies could, for extended periods of time, subject employees to existential fears to induce higher creativity without incurring serious negative side effects (e.g., high employee turnover), nor do we suggest such action to be ethical. However, we nevertheless highlight that the effect of very low moods on creativity in the context of performance-dependent incentives remains an unexplored research question. 


\section{References}

Amabile, T. M. 1982. Children's artistic creativity: Detrimental effects of competition in a field setting. Personality and Social Psychology Bulletin 8 (3): 573-8.

Amabile, T. M. 1988. A model of creativity and innovation in organizations. Research in Organizational Behavior 10: 123-67.

Amabile, T. M., P. Goldfarb, and S. C. Brackfield. 1990. Social influences on creativity: Evaluation, coaction, and surveillance. Creativity Research Journal 3 (1): 6-21.

Amabile, T. M. 1996. Creativity in Context: Update to the Social Psychology of Creativity. Boulder, CO: Westview Press.

Amabile, T. M., S. G. Barsade, J. S. Mueller, and B. M. Staw. 2005. Affect and Creativity at Work. Administrative Science Quarterly 50 (3): 367-403.

Amabile, T. M., and M. G. Pratt. 2016. The dynamic componential model of creativity and innovation in organizations: Making progress, making meaning, Research in Organizational Behavior 36: 157-83.

Ashby, F. G., A. M. Isen, and A. U. Turken. 1999. A neuropsychological theory of positive affect and its influence on cognition. Psychological Review 106: 529-50.

Baas, M., C. K. W De Dreu, and B. A. Nijstad. 2008. A meta-analysis of 25 years of moodcreativity research: Hedonic tone, activation, or regulatory focus? Psychological Bulletin 134 (6): 779-806.

Bartleby. 2019. Employee happiness and business success are linked. The Economist (August 1).

Brink, A. G., B. E. Reichert, and J. M. Sarji. 2020. Does Feedback Matter? The Impact of Incentive Type and Feedback on Creativity. Working Paper, Virginia Commonwealth University.

Byron, K., and S. Khazanchi. 2012. Rewards and creative performance: A meta-analytic test of theoretically derived hypotheses. Psychological Bulletin 138 (4): 809-30.

Carnevale, P. J., and A. M. Isen. 1986. The influence of positive affect and visual access on the discovery of integrative solutions in bilateral negotiation. Organizational Behavior and Human Decision Processes 37 (1): 1-13.

Cianci, A. M., and J. L. Bierstaker. 2009. The Impact of positive and negative mood on the hypothesis generation and ethical judgments of auditors. AUDITING: A Journal of Practice \& Theory 28 (2): 119-44.

Clore, G. L., Schwarz, N., \& Conway, M. (1994). Cognitive causes and consequences of emotion. In R. S. Wyer \& T. K. Srull (Eds.), Handbook of social cognition 2 (1): 323 417. Hillsdale, NJ: Erlbaum.

Cramer, P. 1968. Word association. New York: Academic Press.

Currey, M. 2013. Daily Rituals: How Artists Work. New York: Alfred A. Knopf.

Davis, M. A. 2009. Understanding the relationship between mood and creativity: A metaanalysis, Organizational Behavior and Human Decision Processes 108 (1): 25-38.

Deci, E. L., and R. M. Ryan. 1985. Intrinsic motivation and self-determination in human behavior. New York: Plenum Publishing Co.

Deci, E. L., and R. M. Ryan. 1991. A motivational approach to self: integration in personality. In Nebraska Symposium on Motivation. Nebraska Symposium on Motivation 38: 237-88.

DeVellis, R. F. 1991. Applied social research methods series, Vol. 26. Scale development: Theory and applications. Thousand Oaks, CA, US: Sage Publications, Inc. 
Dietrich, A. 2004. The cognitive neuroscience of creativity. Psychonomic Bulletin \& Review 11 (6): 1011-26.

Duncker, K. 1945. On problem-solving (L. S. Lees, Trans.). Psychological Monographs, 58 (5): i-113.

Estrada, C., A. Isen, and M. Young. 1994. Positive affect improves creative problem solving and influences reported source of practice satisfaction in physicians. Motivation and Emotion 18 (4): 285-99.

Fiedler, K. 2000. Toward an account of affect and cognition phenomena using the BIAS computer algorithm. In J. P. Forgas (Ed.), Feeling and thinking: The role of affect in social cognition (pp. 223-52). Paris: Cambridge University Press.

Finke, R. A. 1996. Imagery, creativity, and emergent structure. Consciousness \& Cognition 5 (3): 381-93.

Fischbacher, U. 2007. Z-tree Zurich toolbox for ready-made economic experiments. Experimental Economics 10 (2): 171-8.

Friedman, R. S., J. Forster, and M. Denzler. 2007. Interactive effects of mood and task framing on creative generation. Creativity Research Journal 19 (2-3): 141-62.

Friedman, R. S., and J. Forster. 2010. Implicit affective cues and attentional tuning: An integrative review. Psychological Bulletin 136(5): 875-93.

Guggenmos, R. D. 2020. The effects of creative culture on real earnings management. Contemporary Accounting Research. In Press.

Guggenmos, R. D., M. D. Piercey, and C. P. Agoglia. 2018. Custom contrast testing: Current trends and a new approach. The Accounting Review 93 (5): 223-44.

Hayes, A. 2013. Introduction to Mediation, Moderation, and Conditional Process Analysis: A Regression-Based Approach. New York, NY: Guilford Press.

Isen, A. M., M. M. Johnson, E. Mertz, and G. F. Robinson. 1985. The influence of positive affect on the unusualness of word associations. Journal of Personality and Social Psychology 48 (6): 1413-26.

Isen, A. M., K. A. Daubman, and G. P. Nowicki. 1987. Positive affect facilitates creative problem solving. Journal of Personality and Social Psychology 52 (6): 1122-31.

Isen, A. M. 1993. Positive affect and decision making. In M. Lewis \& J. M. Haviland (Eds.), Handbook of Emotions, New York: Guilford Press. 261-77.

Isen, A. M. 2002. Missing in action in the AIM: Positive affect's facilitation of cognitive flexibility, innovation, and problem-solving. Psychological Inquiry 13(1): 57-65.

Jennings, P. D., D. McGinnis, S. Lovejoy, and J. Stirling. 2000. Valence and arousal ratings for Velten mood induction statements. Motivation and Emotion 24 (4): 285-96.

Johnson, E. N., D. J. Lowe, and P. M. Reckers. 2016. The influence of mood on subordinates' ability to resist coercive pressure in public accounting. Contemporary Accounting Research 33 (1): 261-87.

Kachelmeier, S. J., B. E. Reichert, and M. G. Williamson. 2008. Measuring and motivating quantity, creativity, or both. Journal of Accounting Research 46 (2): 341-73.

Kachelmeier, S. J., and M. G. Williamson. 2010. Attracting creativity: The initial and aggregate effects of contract selection on creativity-weighted productivity. The Accounting Review 85 (5): 1669-91.

Kachelmeier, S. J., L. W. Wang, and M. G. Williamson. 2019. Incentivizing the creative process: From initial quantity to eventual creativity. The Accounting Review 94 (2): 249-66. 
Mackie, D. M. and L. T. Worth. 1991. Feeling good, but not thinking straight: The impact of positive mood on persuasion. In J. P. Forgas (Ed.), Emotion and social judgment (pp. 201-19). New York: Pergamon Press.

McKee, A. 2014. Being happy at work matters. Harvard Business Review November 14. https://hbr.org/2014/11/being-happy-at-work-matters

Meloy, M. G., Russo, J. E., \& Miller, E. G. (2006). Monetary Incentives and Mood. Journal of Marketing Research, 43(2), 267-275.

Phelps, S. 2019. L. L. Bean, Microsoft, And Amazon Tell Happy Employees To 'Take A Hike!'. Forbes October 19.

https://www.forbes.com/sites/stanphelps/2019/10/19/11-bean-microsoft-and-amazon-tellhappy-employees-to-take-a-hike/\#245cf0957aac

Presslee, A., T. W. Vance, and R. A. Webb. 2013. The Effects of Reward Type on Employee Goal Setting, Goal Commitment, and Performance. The Accounting Review 88 (5): 180531.

Preston, C. 2017. Promoting employee happiness benefits everyone. Forbes December 13. https://www.forbes.com/sites/forbescoachescouncil/2017/12/13/promoting-employeehappiness-benefits-everyone/\#10189ef1581a

Pronto, E. 2016. Are happy workers more productive? Firms' concerns about the well-being of their employees are largely supported by the evidence. IZA World of Labor 315: 1-8. doi: 10.15185/izawol.315

Robbins, T. L., and A. S. DeNisi. 1994. A closer look at interpersonal affect as a distinct influence on cognitive processing in performance evaluations. Journal of Applied Psychology 79 (3): 341-53.

Rosch, E. 1975. Cognitive representations of semantic categories. Journal of Experimental Psychology: General 104 (3): 192-233.

Runco, M. A. 2011. Encyclopedia of Creativity (Second Edition). M.A. Runco and S. Pritzker (Eds.), San Diego, CA: Elsevier, pp. 261-3.

Ryan, R. M. 1982. Control and information in the intrapersonal sphere: An extension of cognitive evaluation theory. Journal of Personality and Social Psychology 43 (3): 45061.

Ryan, R. M., and E. L. Deci. 2000. Self-determination theory and the facilitation of intrinsic motivation, social development, and well-being. American Psychologist 55 (1): 68-78.

Sawers, K. M. 2005. Evidence of choice avoidance in capital-investment judgements. Contemporary Accounting Research 22 (4): 1063-92

Schooler, J. W., S. Ohlsson, and K. Brooks. 1993. Thoughts beyond words: When language overshadows insight. Journal of Experimental Psychology: General 122 (2): 166-83.

Schwartz, N. 1990. Feelings as information: Informational and motivational functions of affective states. In E. T. Huggins \& R. M. Sorrentino (Eds.). Handbook of Motivation and Cognition 2, New York: Guildford Press, 527-61.

Schwarz, N., \& Bless, H. (1991). Happy and mindless, but sad and smart? The impact of affective states on analytic reasoning. In J. P. Forgas (Ed.), Emotion and social judgments (pp. 55-71). Elmsford, NY: Pergamon Press.

Simonton, D. K. 1997. Creative productivity: A predictive and explanatory model of career trajectories and landmarks. Psychological Review 104 (1): 66-89.

Västfjäll, D. 2002. Emotion induction through music: A review of the musical mood induction procedure. Musicae Scientiae Spec Issue (2001-2002): 173-211. 
Velten, E., Jr. 1968. A laboratory task for induction of mood states. Behaviour Research and Therapy 6 (4): 473-82.

Vosburg, S. K. 1998. The effects of positive and negative mood on divergent-thinking performance. Creativity Research Journal: 11: 165-172.

Watson, D., L. A. Clark, and A. Tellegen. 1988. Development and validation of brief measures of positive and negative affect: The PANAS scales. Journal of Personality and Social Psychology 54 (6): 1063-70. 
Figure 1 Experimental procedures

Step 1: Participants follow along as instructions describing the experimental task and the compensation scheme are read aloud. Participants' understanding of instructions is checked, and misunderstandings are corrected before proceeding.

Step 2: Participants read either 60 positive or 60 negative Velten's Mood Statements that are displayed on large screen while they are read aloud by a professional voice actress.

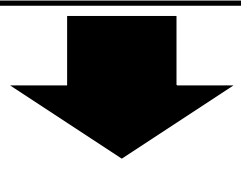

Step 3: Participants spend 20 minutes creating rebus puzzles while classical music validated for either a positive or negative mood is played in the background.

Step 4: Participants complete a post-experimental questionnaire and provide demographic information.

Step 5: Seven independent raters score each rebus puzzle for creativity on a scale of 1-10. Performance dependent payments are calculated, and participants pick up their payment two weeks after the experimental session. 
Figure 2 Examples of rebus puzzles submitted by participants ${ }^{\mathrm{a}}$

Panel A: High-creativity puzzles (4th Quartile)

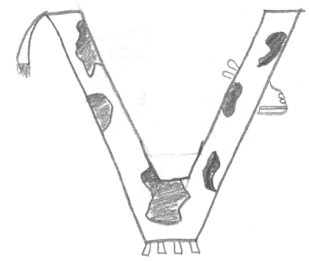

Solution: Movie

Creativity rating: 8.71

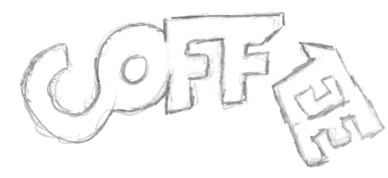

Solution: Coffee break

Creativity rating: 7

Panel B: Low-creativity puzzles (1st Quartile)

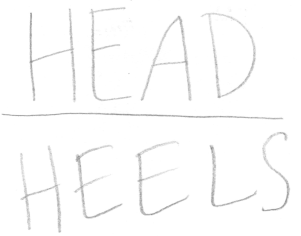

Solution: Head over heels Creativity rating: 3.14

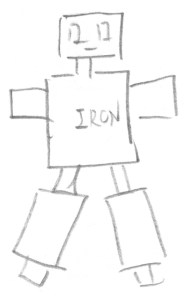

Solution: Iron man

Creativity rating: 2.14

Panel C: Moderate-creativity puzzles (2nd \& 3rd Quartiles)

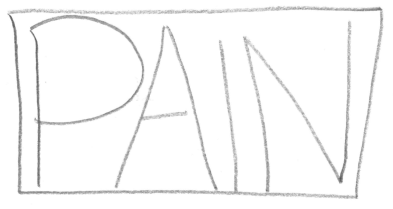

Solution: Painful

Creativity rating: 4.71

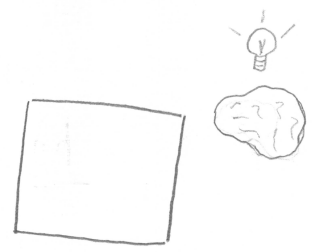

Solution: Think outside the box Creativity rating: 4.71

${ }^{a}$ Each panel provides two examples of representative puzzles created by participants that earned high, low, and moderate creativity ratings. 
Figure 3 Tests of Hypothesis 1: Highly creative output ${ }^{\mathrm{a}}$

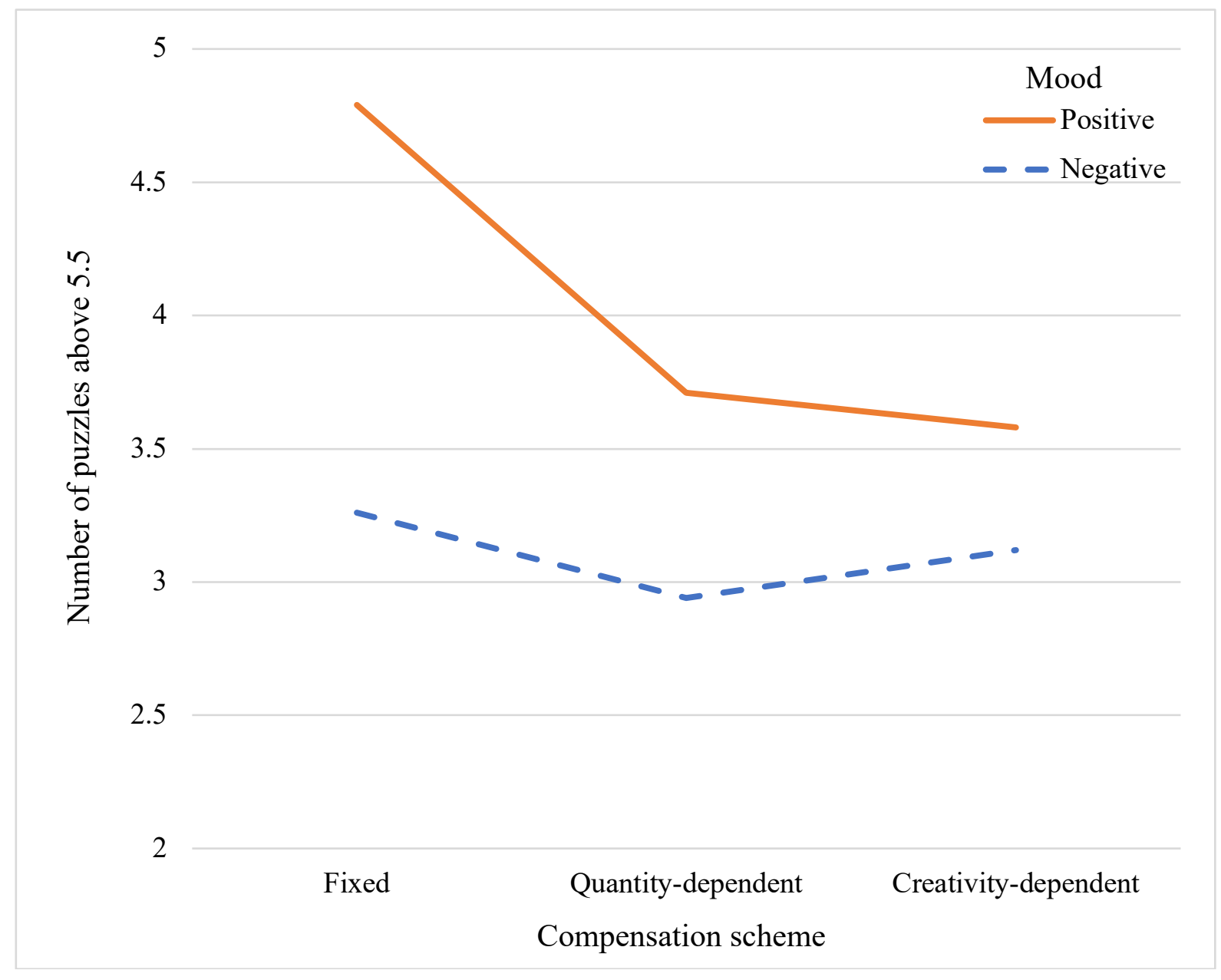

${ }^{\text {a } H i g h l y ~ c r e a t i v e ~ o u t p u t ~}=$ The number of puzzles produced with average ratings in the top quartile of all puzzles (i.e., puzzles with average ratings between 5.5 and 10 ).

We manipulate compensation at three levels (fixed, quantity-dependent, and creativity-dependent) and mood at two levels (positive and negative) as our independent factors. 
Figure 4 Theoretical Moderated Mediation Model of the Effects of Mood and Compensation Contract on Relaxed Playfulness and Performance

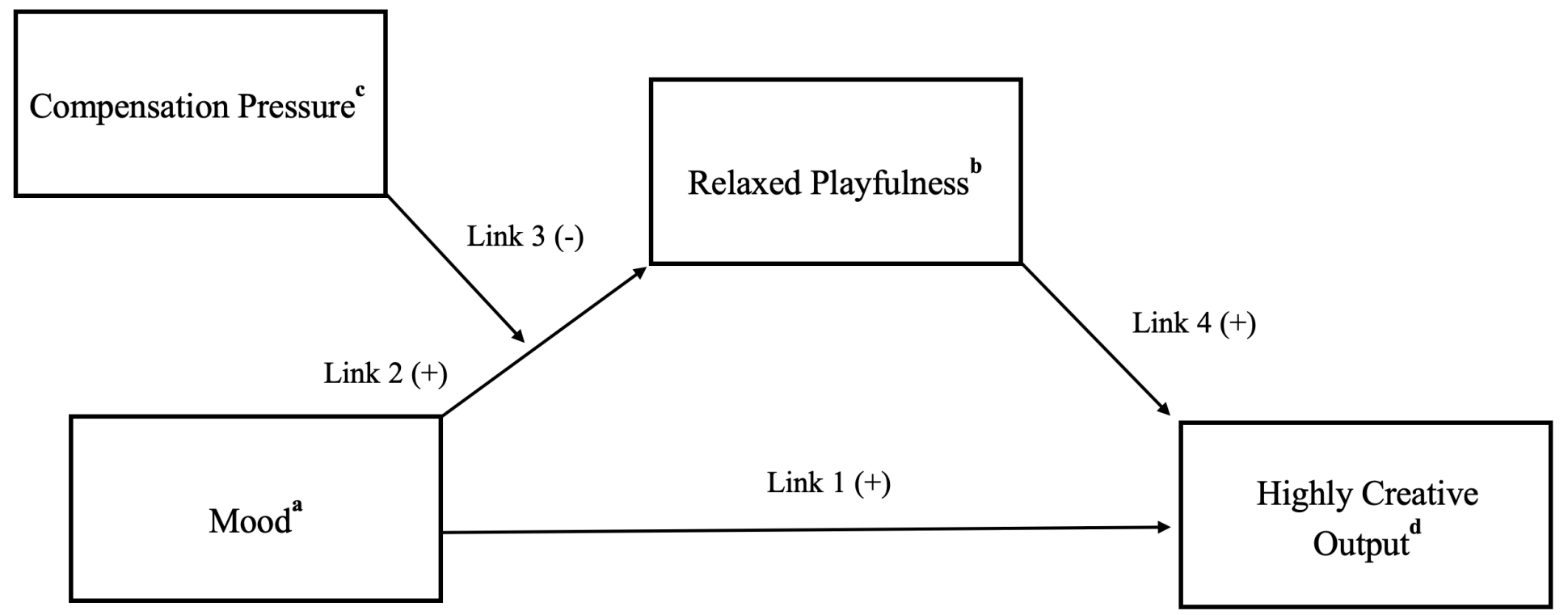

$*, * *, * * *$ Indicate significance at the $0.10,0.05$, and 0.01 levels, respectively (one-tailed).

${ }^{\mathrm{a}}$ Mood is a dichotomous variable where $1=$ positive mood; 0 = negative mood.

${ }^{\mathbf{b}}$ Relaxed Playfulness= The sum of two questions in which participants rated their agreement on a seven-point Likert scale to the following statements: "I was nervous about my ability to construct rebus puzzles," (reverse coded), and "I had the freedom to adopt my own approach to construct rebus puzzles," where $1=$ Strongly Disagree and $7=$ Strongly Agree. The scale was reverse-coded for the first statement noted above for the purpose of producing this graph so that its interpretation was more intuitive. Namely, a larger number represents more relaxed playfulness.

${ }^{\mathfrak{c}}$ Compensation Pressure = The sum of two questions in which participants rated their agreement on a seven-point Likert scale to the following statements: "I focused on enjoying the task without consideration of the impact of my decisions on my compensation" (reverse coded), and "Thinking about my compensation interfered with my ability to concentrate on creating rebus puzzles," where $1=$ Strongly Disagree and $7=$ Strongly Agree. The scale was reverse-coded for the first statement noted above for the purpose of producing this graph so that its interpretation was more intuitive. Namely, a larger number represents more compensation pressure.

${ }^{d}$ Highly creative output $=$ The number of puzzles produced with average ratings in the top quartile of all puzzles (i.e., puzzles with average ratings between 5.5 and 10).

${ }^{\mathrm{e}}$ After controlling for the effect of the mediator variable, task enjoyment, the mood ME is no longer significant, indicating complete mediation by task enjoyment. 
Figure 5 Test of the Theoretical Moderated Mediation Model of the Effects of Mood and Compensation Contract on Relaxed Playfulness and Performance

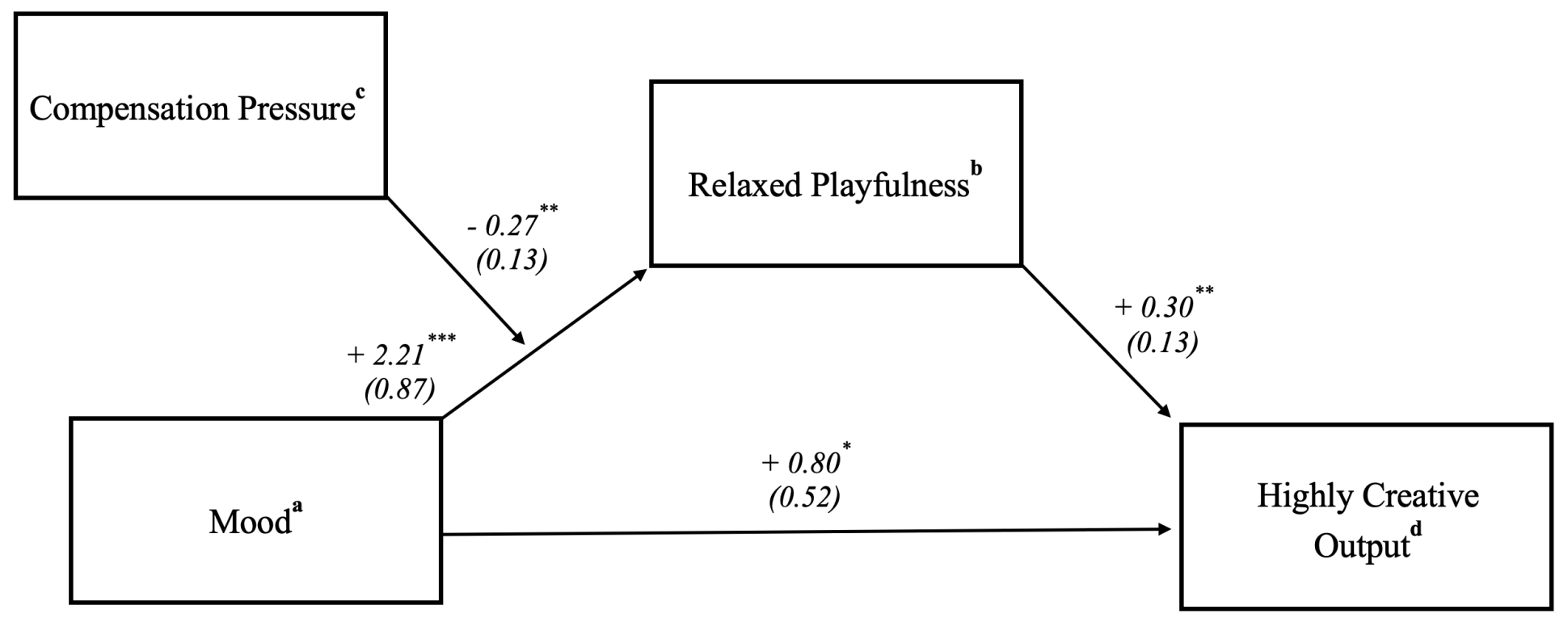

$*, * *, * * *$ Indicate significance at the $0.10,0.05$, and 0.01 levels, respectively (one-tailed).

${ }^{a}$ Mood is a dichotomous variable where $1=$ positive mood; 0 = negative mood.

belaxed Playfulness = The sum of two questions in which participants rated their agreement on a seven-point Likert scale to the following statements: "I was nervous about my ability to construct rebus puzzles," (reverse coded), and "I had the freedom to adopt my own approach to construct rebus puzzles," where 1 = Strongly Disagree and $7=$ Strongly Agree. The scale was reverse-coded for the first statement noted above for the purpose of producing this graph so that its interpretation was more intuitive. Namely, a larger number represents more relaxed playfulness.

${ }^{\mathbf{c}}$ Compensation Pressure = The sum of two questions in which participants rated their agreement on a seven-point Likert scale to the following statements: "I focused on enjoying the task without consideration of the impact of my decisions on my compensation" (reverse coded), and "Thinking about my compensation interfered with my ability to concentrate on creating rebus puzzles," where $1=$ Strongly Disagree and $7=$ Strongly Agree. The scale was reverse-coded for the first statement noted above for the purpose of producing this graph so that its interpretation was more intuitive. Namely, a larger number represents more compensation pressure.

${ }^{\mathrm{d}}$ Highly creative output $=$ The number of puzzles produced with average ratings in the top quartile of all puzzles (i.e., puzzles with average ratings between 5.5 and 10).

${ }^{\mathrm{e}}$ After controlling for the effect of the mediator variable, task enjoyment, the mood ME is no longer significant, indicating complete mediation by task enjoyment. 
Figure 6 Cumulative production of highly creative output for participants in positive mood treatments $^{\mathrm{a}}$

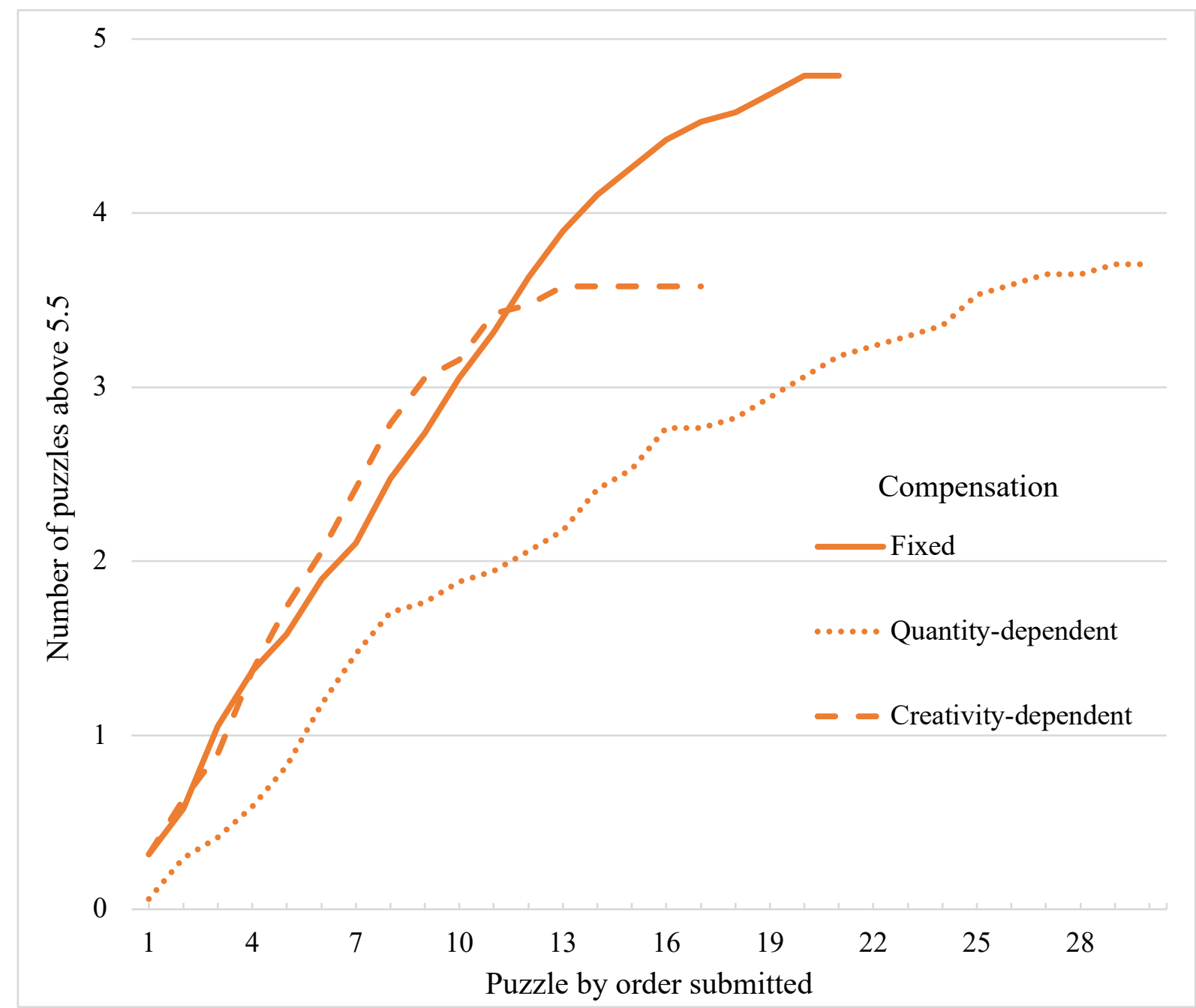

${ }^{a}$ Highly creative output $=$ The number of puzzles produced with average ratings in the top quartile of all puzzles, (i.e., puzzles with average ratings between 5.5 and 10) 
Figure 7 Tests of Hypothesis 2: Low-creativity output ${ }^{\mathrm{a}}$

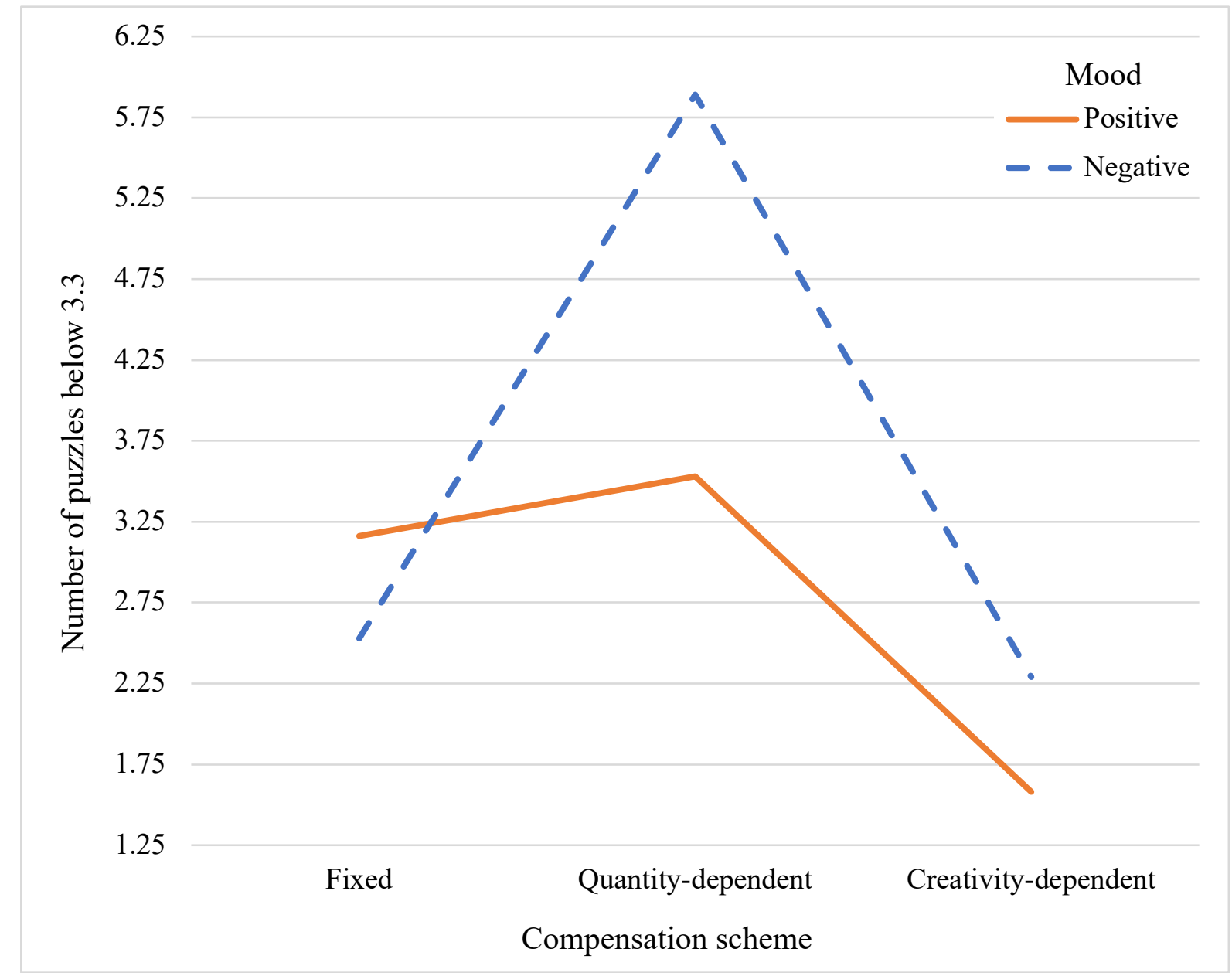

${ }^{\text {a }}$ Low-creativity output $=$ The number of puzzles produced in the lowest quartile of all puzzles, (i.e., puzzles with average rating scores between 1 and 3.3).

We manipulate compensation at three levels (fixed, quantity-dependent, and creativity-dependent) and mood at two levels (positive and negative) as our independent factors. 
TABLE 1

Tests of Hypothesis 1: Highly creative output ${ }^{\mathrm{a}}$

Panel A: Means (Standard Deviations)

\begin{tabular}{|c|c|c|c|c|c|c|}
\hline & \multicolumn{2}{|c|}{$\begin{array}{c}\text { Fixed } \\
\text { compensation }\end{array}$} & \multicolumn{2}{|c|}{$\begin{array}{l}\text { Quantity-dependent } \\
\text { compensation }\end{array}$} & \multicolumn{2}{|c|}{$\begin{array}{l}\text { Creativity-dependent } \\
\text { compensation }\end{array}$} \\
\hline & $\begin{array}{c}\text { Negative } \\
\text { mood } \\
\mathrm{n}=19\end{array}$ & $\begin{array}{c}\text { Positive } \\
\text { mood } \\
\mathrm{n}=19\end{array}$ & $\begin{array}{c}\text { Negative } \\
\text { mood } \\
\mathrm{n}=18\end{array}$ & $\begin{array}{c}\text { Positive } \\
\text { mood } \\
\mathrm{n}=17\end{array}$ & $\begin{array}{c}\text { Negative } \\
\text { mood } \\
\mathrm{n}=17\end{array}$ & $\begin{array}{c}\text { Positive } \\
\text { mood } \\
\mathrm{n}=19\end{array}$ \\
\hline $\begin{array}{l}\text { Highly } \\
\text { creative } \\
\text { output }\end{array}$ & $\begin{array}{c}3.26 \\
(2.16)\end{array}$ & $\begin{array}{c}4.79 \\
(3.05)\end{array}$ & $\begin{array}{c}2.94 \\
(3.37)\end{array}$ & $\begin{array}{c}3.71 \\
(3.57)\end{array}$ & $\begin{array}{c}3.12 \\
(2.12)\end{array}$ & $\begin{array}{c}3.58 \\
(1.98)\end{array}$ \\
\hline
\end{tabular}

Panel B: ANOVA for highly creative output

\begin{tabular}{lrcrcc}
\hline Source of Variation & SS & df & MS & $F$ & $p$-value \\
\hline Compensation & 11.767 & 2 & 5.883 & 0.77 & 0.467 \\
Mood & 22.825 & 1 & 22.825 & 2.98 & 0.044 \\
Compensation* Mood & 5.598 & 2 & 2.799 & 0.37 & 0.695 \\
Error & 789.712 & 103 & 7.667 & & \\
\hline
\end{tabular}

Panel C: Coded contrast for highly creative output

\begin{tabular}{lrcrcc}
\hline Source of Variation & SS & Df & MS & $F$ & $p$-value \\
\hline Contrast $(3,-1,0,-1,0,-1)$ & 39.697 & 1 & 39.697 & 4.88 & 0.013 \\
Residual between-cells variance & $\underline{1.178}$ & $\underline{4}$ & $\underline{\underline{0.295}}$ & 0.04 & 0.996 \\
Total between-cells variance & 40.875 & 5 & 8.175 & & \\
Error & $\underline{789.712}$ & $\underline{103}$ & 7.667 & & \\
Total & 830.587 & 108 & & & \\
Contrast variance residual, $q^{2}$ & $2.88 \%$ & & & & \\
\hline
\end{tabular}

Panel D: Pairwise comparisons for highly creative output

\begin{tabular}{lccc}
\hline Comparison & df & $t$ & $p$-value \\
\hline The effect of mood on highly creative output under fixed compensation & 36 & 1.78 & 0.042 \\
$\begin{array}{l}\text { The effect of mood on highly creative output under quantity-dependent } \\
\text { compensation }\end{array}$ & 33 & 0.65 & 0.260 \\
$\begin{array}{l}\text { The effect of mood on highly creative output under creativity-dependent } \\
\text { compensation }\end{array}$ & 34 & 0.68 & 0.252 \\
\hline
\end{tabular}

${ }^{\text {a }}$ Highly creative output $=$ The number of puzzles produced with average ratings in the top quartile of all puzzles (i.e., puzzles with average ratings between 5.5 and 10). We manipulate compensation at three levels (fixed, quantitydependent, and creativity-dependent) and mood at two levels (positive and negative) as our independent factors.

${ }^{\mathbf{b}}$ We report two-tailed $p$-values for the residual-between cells variance. We report one-tailed $p$-values for the mood main effect, coded contrast and pairwise comparisons. 
TABLE 2

\section{Supplemental Analysis of Hypothesis 1: Total creativity}

Panel A: Means (standard deviations)

\begin{tabular}{|c|c|c|c|c|c|c|}
\hline & \multicolumn{2}{|c|}{$\begin{array}{c}\text { Fixed } \\
\text { compensation }\end{array}$} & \multicolumn{2}{|c|}{$\begin{array}{l}\text { Quantity-dependent } \\
\text { compensation }\end{array}$} & \multicolumn{2}{|c|}{$\begin{array}{l}\text { Creativity-dependent } \\
\text { compensation }\end{array}$} \\
\hline & $\begin{array}{c}\text { Negative } \\
\text { mood } \\
\mathrm{n}=19\end{array}$ & $\begin{array}{c}\text { Positive } \\
\text { mood } \\
\mathrm{n}=19\end{array}$ & $\begin{array}{c}\text { Negative } \\
\text { mood } \\
\mathrm{n}=18\end{array}$ & $\begin{array}{c}\text { Positive } \\
\text { mood } \\
\mathrm{n}=17\end{array}$ & $\begin{array}{c}\text { Negative } \\
\text { mood } \\
\mathrm{n}=17\end{array}$ & $\begin{array}{c}\text { Positive } \\
\text { mood } \\
\mathrm{n}=19\end{array}$ \\
\hline $\begin{array}{l}\text { Total } \\
\text { creativity }\end{array}$ & $\begin{array}{c}59.05 \\
(23.39)\end{array}$ & $\begin{array}{c}69.33 \\
(23.57)\end{array}$ & $\begin{array}{c}73.18 \\
(41.75)\end{array}$ & $\begin{array}{c}76.24 \\
(40.60)\end{array}$ & $\begin{array}{l}51.28 \\
(21.73)\end{array}$ & $\begin{array}{c}49.05 \\
(16.56)\end{array}$ \\
\hline
\end{tabular}

Panel B: Coded contrast for total creativity

\begin{tabular}{lrrrrc}
\hline Source of Variation & \multicolumn{1}{c}{ SS } & df & MS & \multicolumn{1}{c}{$F$} & $p$-value \\
\hline Contrast $(2,0,2,2,-3,-3)$ & 11149.453 & 1 & 11149.453 & 13.00 & $<0.001$ \\
Residual between-cells variance & $\underline{782.792}$ & $\underline{4}$ & $\underline{195.698}$ & 0.23 & 0.922 \\
Total between-cells variance & 11932.245 & 5 & 2386.449 & & \\
Error & $\underline{88343.451}$ & $\underline{103}$ & 857.703 & & \\
Total & 100275.696 & 108 & & & \\
Contrast variance residual, $q^{2}$ & $6.56 \%$ & & & & \\
\hline
\end{tabular}

Panel C: Pairwise comparisons for total creativity

\begin{tabular}{|c|c|c|c|}
\hline Comparison & df & $t$ & $p$-value \\
\hline The effect of mood on total creativity under fixed compensation & 36 & 1.35 & 0.093 \\
\hline $\begin{array}{l}\text { The effect of mood on total creativity under quantity-dependent } \\
\text { compensation }\end{array}$ & 33 & 0.22 & 0.414 \\
\hline $\begin{array}{l}\text { The effect of mood on total creativity under creativity-dependent } \\
\text { compensation }\end{array}$ & 34 & -0.35 & 0.365 \\
\hline
\end{tabular}

${ }^{a}$ Total creativity $=$ The sum of all creativity ratings for all puzzles created by a participant. We manipulate compensation at three levels (fixed, quantity-dependent, and creativity-dependent) and mood on two levels (positive and negative) as our independent factors.

${ }^{\mathrm{b}}$ We report two-tailed $p$-values for the residual-between cells variance. We report one-tailed $p$-values for the coded contrast and pairwise comparisons. 
TABLE 3

Supplemental Analysis of Hypothesis 1: Most creative card $^{\mathrm{a}}$

Panel A: Means (standard deviations)

\begin{tabular}{|c|c|c|c|c|c|c|}
\hline & \multicolumn{2}{|c|}{$\begin{array}{c}\text { Fixed } \\
\text { compensation }\end{array}$} & \multicolumn{2}{|c|}{$\begin{array}{l}\text { Quantity-dependent } \\
\text { compensation }\end{array}$} & \multicolumn{2}{|c|}{$\begin{array}{l}\text { Creativity-dependent } \\
\text { compensation }\end{array}$} \\
\hline & $\begin{array}{c}\text { Negative } \\
\text { mood } \\
\mathrm{n}=19\end{array}$ & $\begin{array}{c}\text { Positive } \\
\text { mood } \\
\mathrm{n}=19\end{array}$ & $\begin{array}{c}\text { Negative } \\
\text { mood } \\
\mathrm{n}=18\end{array}$ & $\begin{array}{c}\text { Positive } \\
\text { mood } \\
\mathrm{n}=17\end{array}$ & $\begin{array}{c}\text { Negative } \\
\text { mood } \\
\mathrm{n}=17\end{array}$ & $\begin{array}{c}\text { Positive } \\
\text { mood } \\
n=19\end{array}$ \\
\hline $\begin{array}{l}\text { Most } \\
\text { creative } \\
\text { card }\end{array}$ & $\begin{array}{c}6.62 \\
(0.62)\end{array}$ & $\begin{array}{c}7.04 \\
(0.83)\end{array}$ & $\begin{array}{c}6.40 \\
(0.86)\end{array}$ & $\begin{array}{c}6.46 \\
(0.90)\end{array}$ & $\begin{array}{c}6.90 \\
(1.02)\end{array}$ & $\begin{array}{c}6.91 \\
(0.89)\end{array}$ \\
\hline
\end{tabular}

Panel B: Coded contrast for most creative card

\begin{tabular}{lrrrrc}
\hline Source of Variation & SS & df & MS & \multicolumn{1}{c}{$F$} & $p$-value \\
\hline Contrast $(2,-2,-2,-2,2,2)$ & 5.615 & 1 & 5.615 & 7.667 & 0.004 \\
Residual between-cells variance & $\underline{0.712}$ & $\underline{4}$ & $\underline{0.178}$ & 0.23 & 0.922 \\
Total between-cells variance & 6.327 & 5 & 1.2654 & & \\
Error & $\underline{75.433}$ & $\underline{103}$ & 0.732 & & \\
Total & 81.760 & 108 & & & \\
Contrast variance residual, $q^{2}$ & $11.25 \%$ & & & & \\
\hline
\end{tabular}

Panel C: Pairwise comparisons for most creative card

\begin{tabular}{lccc}
\hline Comparison & df & $t$ & $p$-value \\
\hline $\begin{array}{l}\text { The effect of mood on most creative card under fixed } \\
\text { compensation }\end{array}$ & 36 & 1.75 & 0.044 \\
$\begin{array}{l}\text { The effect of mood on most creative card under quantity-dependent } \\
\text { compensation }\end{array}$ & 33 & 0.22 & 0.414 \\
$\begin{array}{l}\text { The effect of mood on most creative card under creativity- } \\
\text { dependent compensation }\end{array}$ & 34 & 0.03 & 0.487 \\
\hline
\end{tabular}

${ }^{\text {a }}$ Most creative card $=$ The score for the puzzle with the highest average creativity rating created by a participant. We manipulate compensation at three levels (fixed, quantity-dependent, and creativity-dependent) and mood on two levels (positive and negative) as our independent factors.

${ }^{\mathrm{b}}$ We report two-tailed $p$-values for the residual-between cells variance. We report one-tailed $p$-values for the coded contrast and pairwise comparisons. 
TABLE 4

Tests of Hypothesis 2: Low-creativity output ${ }^{\mathrm{a}}$

Panel A: Means (standard deviations)

\begin{tabular}{|c|c|c|c|c|c|c|}
\hline & \multicolumn{2}{|c|}{$\begin{array}{c}\text { Fixed } \\
\text { compensation }\end{array}$} & \multicolumn{2}{|c|}{$\begin{array}{l}\text { Quantity-dependent } \\
\text { compensation }\end{array}$} & \multicolumn{2}{|c|}{$\begin{array}{c}\text { Creativity-dependent } \\
\text { compensation }\end{array}$} \\
\hline & $\begin{array}{c}\text { Negative } \\
\text { mood } \\
\mathrm{n}=19\end{array}$ & $\begin{array}{c}\text { Positive } \\
\text { mood } \\
\mathrm{n}=19\end{array}$ & $\begin{array}{c}\text { Negative } \\
\text { mood } \\
\mathrm{n}=18\end{array}$ & $\begin{array}{c}\text { Positive } \\
\text { mood } \\
\mathrm{n}=17\end{array}$ & $\begin{array}{c}\text { Negative } \\
\text { mood } \\
\mathrm{n}=17\end{array}$ & $\begin{array}{c}\text { Positive } \\
\text { mood } \\
\mathrm{n}=19\end{array}$ \\
\hline $\begin{array}{l}\text { Low- } \\
\text { creativity } \\
\text { output }^{\mathbf{b}}\end{array}$ & $\begin{array}{l}2.53 \\
(2.17)\end{array}$ & $\begin{array}{l}3.16 \\
(2.01)\end{array}$ & $\begin{array}{c}5.89 \\
(5.05)\end{array}$ & $\begin{array}{l}3.53 \\
(2.67)\end{array}$ & $\begin{array}{l}2.29 \\
(2.09)\end{array}$ & $\begin{array}{l}1.58 \\
(1.43)\end{array}$ \\
\hline
\end{tabular}

Panel B: Coded contrast for low-creativity output

\begin{tabular}{lrrrrc}
\hline Source of Variation & \multicolumn{1}{c}{ SS } & df & MS & $F$ & $p$-value \\
\hline Contrast $(1,1,1,-5,1,1)$ & 160.761 & 1 & 160.761 & 20.41 & 0.001 \\
Residual between-cells variance & $\underline{43.453}$ & $\underline{4}$ & $\underline{10.863}$ & 1.38 & 0.246 \\
Total between-cells variance & 204.214 & 5 & 40.843 & & \\
Error & $\underline{811.437}$ & $\underline{103}$ & 7.878 & & \\
Total & 1015.651 & 108 & & & \\
Contrast variance residual, $q^{2}$ & $21.28 \%$ & & & & \\
\hline
\end{tabular}

Panel C: Pairwise comparisons for low-creativity output

\begin{tabular}{lccc}
\hline Comparison & $\mathrm{df}$ & $t$ & $p$-value \\
\hline The effect of mood on low-creativity output under fixed compensation & 36 & 0.931 & 0.179 \\
$\begin{array}{l}\text { The effect of mood on low-creativity output under quantity-dependent } \\
\text { compensation }\end{array}$ & 33 & -1.712 & 0.048 \\
$\begin{array}{l}\text { The effect of mood on low-creativity output under creativity-dependent } \\
\text { compensation }\end{array}$ & 34 & -1.21 & 0.117 \\
\hline
\end{tabular}

${ }^{\text {a }}$ We manipulate compensation at three levels (fixed, quantity-dependent, and creativity-dependent) and mood on two levels (positive and negative) as our independent factors.

${ }^{\mathrm{b}}$ Low-creativity output $=$ The number of puzzles produced in the first quartile of all puzzles, (i.e., puzzles with average rating scores between 1 and 3.3).

${ }^{c}$ We report two-tailed $p$-values for the residual-between cells variance. We report one-tailed $p$-values for the coded contrast and pairwise comparisons. 
TABLE 5

Supplemental Analysis of Hypothesis 2: Lowest creativity ${ }^{\mathrm{a}}$

Panel A: Means (standard deviations)

\begin{tabular}{|c|c|c|c|c|c|c|}
\hline & \multicolumn{2}{|c|}{$\begin{array}{c}\text { Fixed } \\
\text { compensation }\end{array}$} & \multicolumn{2}{|c|}{$\begin{array}{l}\text { Quantity-dependent } \\
\text { compensation }\end{array}$} & \multicolumn{2}{|c|}{$\begin{array}{c}\text { Creativity-dependent } \\
\text { compensation }\end{array}$} \\
\hline & $\begin{array}{c}\text { Negative } \\
\text { mood } \\
\mathrm{n}=19\end{array}$ & $\begin{array}{c}\text { Positive } \\
\text { mood } \\
\mathrm{n}=19\end{array}$ & $\begin{array}{c}\text { Negative } \\
\text { mood } \\
\mathrm{n}=18 \\
\end{array}$ & $\begin{array}{c}\text { Positive } \\
\text { mood } \\
\mathrm{n}=17\end{array}$ & $\begin{array}{c}\text { Negative } \\
\text { mood } \\
\mathrm{n}=17\end{array}$ & $\begin{array}{c}\text { Positive } \\
\text { mood } \\
\mathrm{n}=19\end{array}$ \\
\hline $\begin{array}{l}\text { Lowest } \\
\text { creativity }\end{array}$ & $\begin{array}{c}2.81 \\
(0.60)\end{array}$ & $\begin{array}{c}2.68 \\
(0.65)\end{array}$ & $\begin{array}{c}2.25 \\
(0.69)\end{array}$ & $\begin{array}{c}2.71 \\
(0.63)\end{array}$ & $\begin{array}{c}2.69 \\
(0.79)\end{array}$ & $\begin{array}{c}2.83 \\
(1.00)\end{array}$ \\
\hline
\end{tabular}

Panel B: Coded contrast for lowest creativity

\begin{tabular}{lccccc}
\hline Source of Variation & SS & df & MS & $F$ & $p$-value \\
\hline Contrast $(1,1,1,-5,1,1)$ & 3.719 & 1 & 3.719 & 6.74 & 0.006 \\
Residual between-cells variance & $\underline{0.395}$ & $\underline{4}$ & $\underline{0.099}$ & 0.18 & 0.949 \\
Total between-cells variance & 4.114 & 5 & 0.823 & & \\
Error & $\underline{56.846}$ & $\underline{103}$ & 0.552 & & \\
Total & 60.960 & 108 & & & \\
Contrast variance residual, $q^{2}$ & $9.60 \%$ & & & & \\
\hline
\end{tabular}

Panel C: Pairwise comparisons for lowest creativity

\begin{tabular}{lccc}
\hline Comparison & df & $t$ & $p$-value \\
\hline $\begin{array}{l}\text { The effect of mood on lowest creativity under fixed compensation } \\
\text { The effect of mood on lowest creativity under quantity-dependent }\end{array}$ & 36 & -0.63 & 0.268 \\
$\begin{array}{l}\text { compensation } \\
\text { The effect of mood on lowest creativity under creativity-dependent } \\
\text { compensation }\end{array}$ & 34 & 2.05 & 0.024 \\
\hline
\end{tabular}

${ }^{\text {a }}$ We manipulate compensation at three levels (fixed, quantity-dependent, and creativity-dependent) and mood on two levels (positive and negative) as our independent factors.

${ }^{\mathrm{b}}$ Lowest creativity $=$ The puzzle with the lowest average creativity rating for each participant.

${ }^{c}$ We report two-tailed $p$-values for the residual-between cells variance. We report one-tailed $p$-values for the coded contrast and pairwise comparisons. 